Stratospheric intrusions

A. Carré et al.

\title{
Stratospheric intrusions induced by a Rossby Wave breaking and its interaction with the subtropical jet during PICO3 campaign
}

A. Carré ${ }^{1}$, F. Ravetta ${ }^{2}$, J.-P. Cammas ${ }^{1}$, P. Mascart ${ }^{1}$, J. Duron ${ }^{1}$, G. Ancellet ${ }^{2}$, and D. Lambert ${ }^{1}$

${ }^{1}$ Laboratoire d'Aérologie, Observatoire Midi-Pyrénées, Toulouse, France

${ }^{2}$ Service d'Aéronomie, Institut Pierre Simon Laplace, Paris, France

Received: 23 June 2005 - Accepted: 25 July 2005 - Published: 24 October 2005

Correspondence to: A. Carré (cara@aero.obs-mip.fr)

(C) 2005 Author(s). This work is licensed under a Creative Commons License.

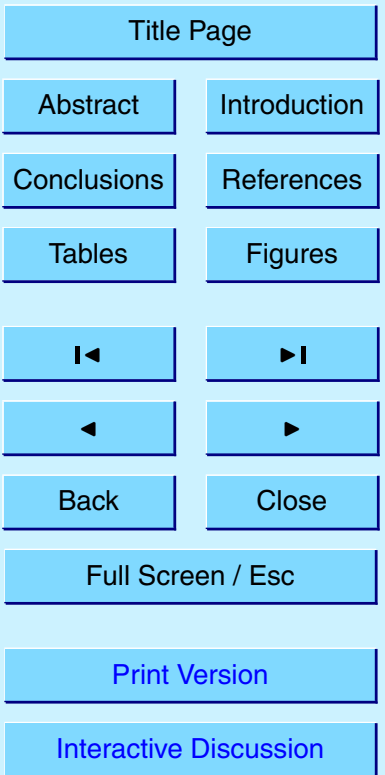

EGU 


\section{Abstract}

This study documents several processes of stratosphere-troposphere transport (STT) in the subtropical region. A case study of the interaction between a Rossby Wave breaking over the Canary Islands and a subtropical vortex core situated further south 5 is analysed with ozone airborne measurements (in-situ and Lidar). The investigation is conducted using a Reverse Domain Filling technique to reconstruct high-resolution potential vorticity fields with a Lagrangian approach and with simulations of a mesoscale model. Results show irreversible STT associated with tropopause folding, Rossby Wave Breaking and the filamentation of the subtropical vortex core.

\section{Introduction}

The troposphere and the stratosphere are characterised by very different dynamical and chemical properties, involving strong gradients of potential vorticity (PV), chemical species like ozone $\left(\mathrm{O}_{3}\right)$ and relative humidity $(\mathrm{RH})$ at the tropopause. Despite the isentropic PV gradient acting as a dynamical barrier for the transport of air masses across the tropopause, several mechanisms of exchange exist (see Holton et al., 1995, for a general overview on stratosphere-troposphere exchanges). In this paper, the general term STE will refer to stratosphere-troposphere exchange in both directions, while the specific term STT will refer to stratosphere-troposphere transport and TST will refer to troposphere-stratosphere transport. For mid-latitudes, Keyser and Shapiro (1986) reviewed the dynamical properties of baroclinic waves leading to tropopause folds and cut-off lows. Numerous case studies have documented STE associated with tropopause folds (e.g. Danielsen, 1968), with cut-off lows (e.g. Gouget et al., 2000) and with other observed meso-scale structures resulting from the fragmentation of stratospheric intrusions near the mid-latitude tropopause (Appenzeller et al., 1996a). For the subtropics, Postel and Hitchman (1999) and Waugh and Polvani (2000) produced a climatology of Rossby Wave Breaking (RWB) and reviewed the dynamical proper-
ACPD

5, 10301-10337, 2005

\section{Stratospheric intrusions}

A. Carré et al.

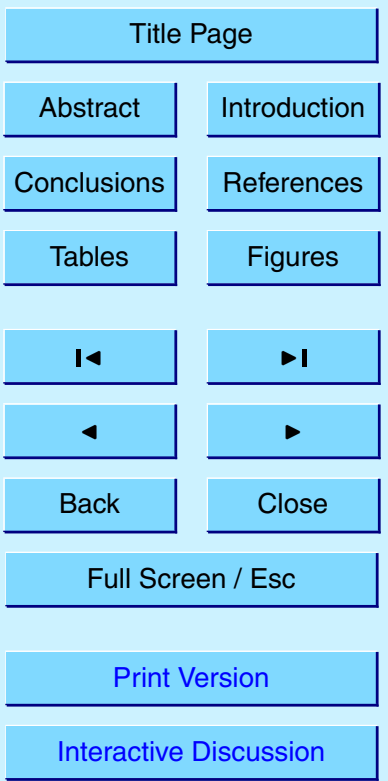

EGU 
ties leading to the associated irreversible deformation of PV contours on isentropic surfaces across the tropopause. In comparison, fewer case studies of RWB in the subtropics have been made (e.g. Scott et al., 2001; Baray et al., 2003) but those that exist show that substantial STT is involved. Quantifying the transport associated with 5 the wide variety of STE presents a significant challenge on account of the many multiscale processes involved, as witnessed by the large range of modelled estimates of stratosphere to troposphere flux of ozone, from $1400 \mathrm{Tg} / \mathrm{yr}$ (Crutzen et al., 1999) to $400 \mathrm{Tg} / \mathrm{yr}$ (Hauglustaine et al., 1998). Sensitivity arises from the surface taken to represent the tropopause across which fluxes are calculated. In most studies, the dy10 namical tropopause is used, area based on a potential vorticity threshold expressed in potential vorticity units $\left(1 \mathrm{pvu}=10^{-6} \mathrm{~m}^{2} \mathrm{Ks}^{-1} \mathrm{~kg}^{-1}\right)$. However, the threshold ranges between $1.6 \mathrm{pvu}$ (WMO, 1986) and $3.5 \mathrm{pvu}$ (Hoerling et al., 1991). Difficulties also arise from the method used. Eulerian methods that estimate the motion of air relative to the tropopause have been popularized by Wei (1987) but are highly sensitive to inaccuracies in the underlying data (Wirth and Egger, 1999). Many authors have recently developed a Lagrangian approach (Stohl, 2001; Wernli and Bourqui, 2002; James et al., 2003a, b; Sprenger et al., 2003) and have demonstrated that computing the crosstropopause flux alone is not sufficient to provide an understanding of the impact on the chemistry of these layers and the impact on climate. In fact, the subsequent paths of air crossing the tropopause should be taken into account, which is not the case in the traditional methods using eulerian diagnostics (e.g. Wei, 1987). Clearly, the significance for STE will differ between deep or shallow transport, rapid or long residence pathways, and finally between reversible and irreversible transport. Based on the 15year ECMWF reanalyses, James et al. (2003b) show that, unlike shallow STE events, deep stratospheric intrusions present a winter maximum, thus a specific seasonal cycle. At the same time, more than $90 \%$ of all cross-tropopause flows return within $6 \mathrm{~h}$ and may not have a large impact on the seasonal cycle of stratospheric ozone in the troposphere. However, use of the ECMWF reanalysis data limited the scales of motion considered in previous studies because the best resolution of the input data was $6 \mathrm{~h}$ in
ACPD

$5,10301-10337,2005$

\section{Stratospheric intrusions}

A. Carré et al.

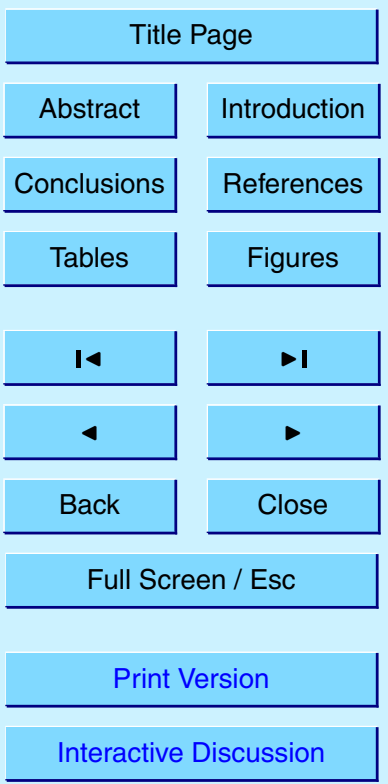

EGU 
time and $1^{\circ}$ in space.

In this paper we study an episode of RWB and its interaction with the subtropical jet with the objectives to infer STE structures from experimental evidence, and to detail from numerical simulations, the associated STTs. Without quantifying the associated 5 transport, the aim is, as a first step, to infer the significance of these STTs in term of irreversibility or not. The case study is documented by the airborne campaign PICO3 which took place in October 2000 over the Canary Islands $\left(28^{\circ} \mathrm{N}-14^{\circ} \mathrm{W}\right)$. The aim of this campaign was to document the structure of stratospheric filaments in the subtropical region linked to RWB at mid latitudes. The aircraft was equipped with in-situ and 10 Lidar instruments for $\mathrm{O}_{3}$. Table 1 resumes the occurrence of the PICO3 flights used in that study, and the stratospheric structures sampled during each flight. The structure of the paper is as follows. In Sect. 2 we present the synoptic situation from ECMWF analyses and, in particular, the evolution of the RWB at mid-latitude. Then, we describe with observations and model results the associated structures leading to STE:

15 a tropopause fold, a midlatitude upper-level trough filament and a subtropical vortex core leading to another filament along the subtropical jet. In Sect. 3, we discuss the irreversibility of STT for each structure. Finally, conclusions are drawn in Sect. 4.

\section{Several cases of subtropical STE}

2.1. Meteorological context, numerical tools, and instrumentation

20 ECMWF data were chosen for the description of the meteorological situation. They are composed of 6-hourly analyses (00:00, 06:00, 12:00 and 18:00 UTC) with 60 vertical levels from the surface up to $0.1 \mathrm{hPa}$ plus intermediate 3-hourly forecasts (03:00, 09:00, 15:00 and 21:00 UTC). The ECMWF archive is spectral and is retrieved with an equivalent horizontal resolution of about $40 \mathrm{~km} \times 40 \mathrm{~km}$. Figure 1 shows the mid25 latitude Rossby Wave Breaking (RWB) which occurred during the PICO3 campaign. This wave life cycle corresponds to the so called 'LC1' type of RWB event described

ACPD

5, 10301-10337, 2005

\section{Stratospheric intrusions}

A. Carré et al.

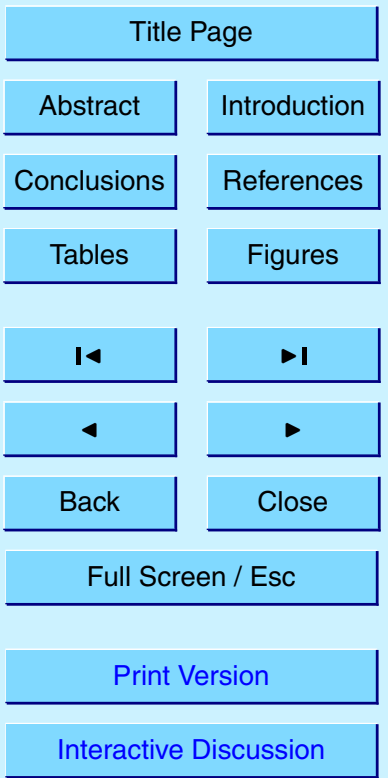

EGU 
by Thorncroft et al. (1993). On 19 and 20 October, southward streching resulted in the breaking of this Rossby wave associated with the strong anticyclonic curved jet stream (Figs. $1 \mathrm{~b}$ and $\mathrm{c}$ ). Finally, this wave continued breaking and moving eastward on 21 October (Fig. 1d). At the southernmost tip of the wave, we observe the formation of a 5 stratospheric filament due to the thinning of the advected high-PV air masses. PICO3 flights probed this filament over the Canary Islands on 20 October during flights 39 and 40 (Fig. 1c), and on 21 October during flight 41 (Fig. 1d).

On 18 October (Fig. 1a) the PV distribution between 15 and $30^{\circ} \mathrm{N}$ was characterised by a subtropical vortex which was documented by PICO3 flight number 37 . As the baro10 clinic wave broke over the region, the subtropical vortex evolved towards a subtropical zonal filament (Figs. 1c and d) with a predominant contribution of the meridional wind shear component of the potential vorticity compared to the curvature component (Bell and Keyser, 1993). The zonal state of the subtropical jet was documented by PICO3 flight number 39 on 20 October, 15:00 UTC (see red flight path on Fig. 1c), at a time 15 when the upper level filament of the baroclinic wave was further north. PICO3 flight number 41 on 21 October, 09:00 UTC (Fig. 1d) sampled it again at a time when it was coming into contact with the upper level filament according to ECMWF analyses.

To document the mesoscale aspects of the case study, several model runs were performed with the Non-Hydrostatic meso-scale model Meso-NH. The simulation period extended from 20 October at 00:00 UTC to 21 October at 09:00 UTC, to include the three flights 39, 40 and 41. The Meso-NH model is based on the anelastic equations and was developed by the Centre National de Recherche Météorologiques (CNRM) and the Laboratoire d'Aérologie (Lafore et al., 1998). Full physical parametrisations are included in this model: Kain-Bechtold convective scheme, microphysical scheme with ice, turbulent scheme TKE, surface exchange ISBA with resolution physiography, and radiation scheme of ECMWF (Morcrette, 1991). The domain of simulation is the region $39^{\circ} \mathrm{W}-6^{\circ} \mathrm{E}, 7^{\circ} \mathrm{N}-49^{\circ} \mathrm{N}$ centered on the Canary Islands, with a horizontal resolution of $30 \mathrm{~km}$ and 152 vertical levels to give a good representation at the tropopause region: the top of the model is at $40 \mathrm{~km}$ altitude with a vertical resolution of $300 \mathrm{~m}$ constant
ACPD

$5,10301-10337,2005$

\section{Stratospheric intrusions}

A. Carré et al.

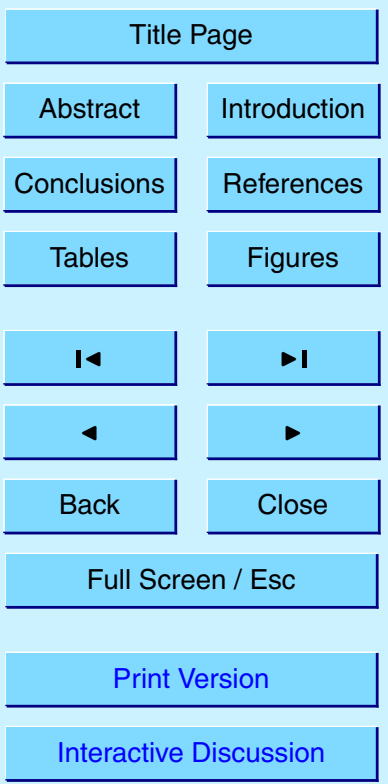

EGU 
from mid-troposphere to model top. Chemical modules can also be activated on-line to simulate chemical processes (Meso-NH becomes "Meso-NH-C") with online chemistry (Crassier et al., 2000). In addition, each run includes i) Lagrangian tracers to compute backward or forward trajectories, and ii) $\mathrm{PICO} 3$ flight emulation to give some direct 5 comparisons with the in-situ measurements. Figure 2 presents a temporal evolution of the Meso-NH PV field at flight levels. The dynamical pattern delivered by the model gathers STE structures shown by the ECMWF analyses, i.e. the southernmost tip of the upper-level trough and the associated filament, and the subtropical vortex evolution to a subtropical filament. A detailed evaluation of the simulation over the case study, 10 made (not shown) by comparing synthetic and METEOSAT observed radiances in the infrared and water vapour channels using a "model-to-satellite" approach (Chaboureau et al., 2000), showed good results. Consequently, Meso-NH outputs are jointly used with aiborne observations to document the STE structures.

Because of the predominant relevance of ozone to detect stratospheric intrusion 15 near the tropopause region, Fig. 3 displays the in-situ $\mathrm{O}_{3}$ measurements and $\mathrm{O}_{3}$ simulated by Meso-NH-C during the three flights 39, 40 and 41 . In-situ measurements were sampled every $4 \mathrm{~s}$ (corresponding to a horizontal resolution of about $1 \mathrm{~km}$ ). Ozone measurements were provided by the MOZAIC instrument (Marenco et al., 1998), a dual beam UV absorption instrument with a detection limit of 2 ppbv and overall accuracy of $\pm[2 \mathrm{ppbv}+2 \%]$. A good general agreement is observed on Fig. 3; a more detailed comparaison is given below. Note that flights 40 and 41 made a loop trajectory (Figs. 2b, c), so measurements present some symmetry of shape (around 08:30 UTC for flight 41 Fig. 3d for instance).

To document the stratospheric structures and complete the ECMWF data, Meso-NH simulations and observations, we also used the Reverse Domain Filling (RDF) technique on the ECMWF analyses. In fact, fields derived from meteorological analyses do not resolve fine scales of motion. This can be usefully remedied by the RDF technique (Sutton et al., 1994) which allows the fine-scale structure of PV to be examined (Schoeberl et al., 1995; Hegglin et al., 2004). In this technique PV is used as a conservative

\section{ACPD}

5, 10301-10337, 2005

\section{Stratospheric intrusions}

A. Carré et al.

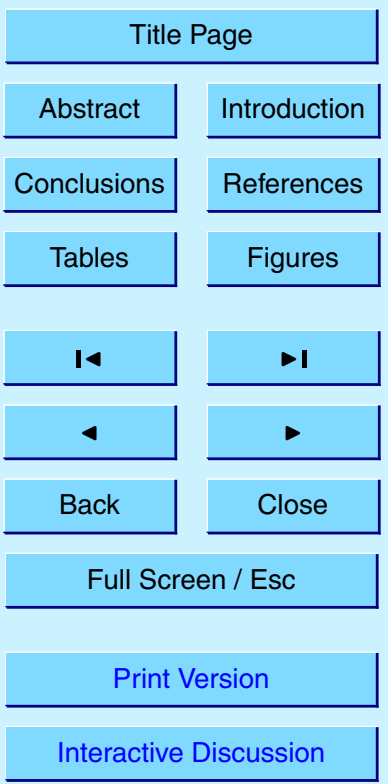

EGU 
tracer. Its field at time " $t$ " is reconstructed with values taken at a time " $t-\Delta t$ " by a set of backward trajectories regularly gridded between time ' $t$ ' and time " $t-\Delta t$ ". Here, " $\Delta t$ " is the backward trajectories integration time. We take it equal to $24-36 \mathrm{~h}$ as no additional information on the PV field is gained for larger time periods (not shown). Backward 5 trajectories are performed by the Lagrangian Analysis Tool (LAGRANTO) (Wernli and Davies, 1997) using 3-hourly sequences of ECMWF wind fields. As a preview, Fig. 6 presents the reconstructed PV field (noted RDFPV, graph $\mathrm{c}$ ) and the PV field from the ECMWF analysis (graph d) on 20 October, 18:00 UTC. These two PV structures are compared to the Meso-NH-C O $\mathrm{O}_{3}$ field (graph b) and to the Lidar $\mathrm{O}_{3}$ observations 10 (graph a) during the flight 40. The Airborne Lidar ALTO was developed by the Service d'Aéronomie (Ancellet and Ravetta, 1998). Using a UV differential absorption Lidar (DIAL), ozone vertical profiles have been measured from $500 \mathrm{~m}$ up to $6 \mathrm{~km}$ above the aircraft. On ozone vertical cross sections along flight tracks, each coloured pixel is about $40 \mathrm{~km}$ wide and $150 \mathrm{~m}$ thick. This give an idea of the horizontal and vertical resolution of this lidar during this campaign. White patches have been applied when aerosol layers or cirrus have made ozone measurement inaccurate. Stratospheric intrusions observed with the lidar are well reproduced by RDFPV field. Given their horizontal resolution, the PV field derived from ECMWF analysis and the $\mathrm{O}_{3}$ field computed by Meso-NH-C are smoother than the RDFPV field and do not always perfectly match the observations. This will be further discussed below.

\subsection{Wave breaking at mid-latitudes}

The Rossby Wave Breaking occurring at mid-latitudes led to three different structures of stratospheric air-mass intrusions into the upper troposphere: a tropopause fold, an upper-level trough-filament (noted ULTF hereafter) and its intrusion further down into

the troposphere. These three structures are described in the two following subsections.
ACPD

5, 10301-10337, 2005

\section{Stratospheric intrusions}

A. Carré et al.

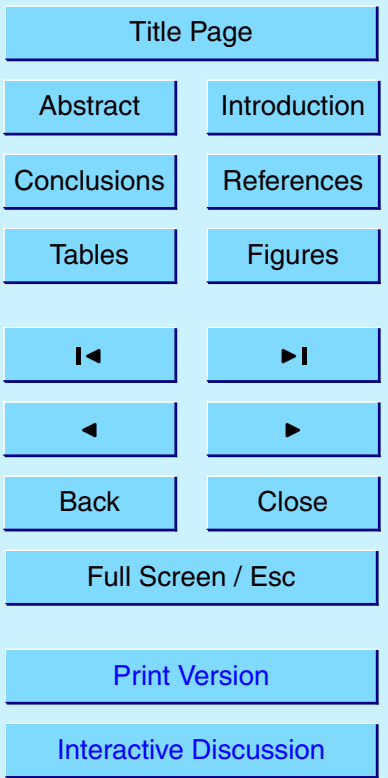

EGU 
In-situ $\mathrm{O}_{3}$ measurements during the take-off of flight 40 are displayed on Figs. $3 \mathrm{c}$ and

$4 a$. They show ozone-rich layers (up to $80 \mathrm{ppbv}$ ) and we investigate those noted Max1 and Max2 at low altitudes, around $5.5 \mathrm{~km}$ and $8 \mathrm{~km}$, respectively. To determine the origin of ozone layers Max1 and Max2, we computed Meso-NH 18-h backward trajectories of air parcels (not shown) initialized along the take-off path of flight 40 back to 20 October, 00:00 UTC. Some air parcels were situated in a tropopause fold from 00:00 to 06:00 UTC. Figure $4 \mathrm{~b}$ shows the structure of this fold at 06:00 UTC, with the Meso-NH PV field. The tropopause is defined dynamically as the 2 pvu isoline of potential vorticity following Hoskins et al. (1985). The PV structure displays the well known tropopause fold structure developed in relationship with an upper level frontal system as described by Danielsen (1968) and Keyser and Shapiro (1986). The fold develops on the western flank of the trough at $320 \mathrm{~K}$. High PV air (around $1 \mathrm{pvu}$ ) penetrates into the troposphere down to $7 \mathrm{~km}$ above ground with a transverse width of fold of about $15100 \mathrm{~km}$. The red cross marks an example of an air parcel which is located in the fold at 06:00 UTC and at the location of the in-situ $\mathrm{O}_{3}$ maximum labelled Max1 at 18:00 UTC. Between 06:00 and 18:00 UTC, this air parcel subsided by about $3 \mathrm{~km}$, covering about $2000 \mathrm{~km}$ on a horizontal plane southeasterly over the Atlantic Ocean. Other backward trajectories confirm that the stratospheric origin of Max2 is associated with the same 20 folding process (not shown). Note, however, that the fine scale vertical layering seen on Fig. $4 a$ is not totally explained as there is no evidence in backward trajectories of a tropospheric-origin layer associated to Min1. The vertical resolution of the Meso-NH run may not be sufficient for such an objective.

\subsubsection{Upper level trough filamentation}

25 Figure $5 \mathrm{c}$ presents the vertical time series of $\mathrm{O}_{3}$ Lidar measurements along flight 39 path (section I-J on Fig. 2a). It shows a tropopause at about $14 \mathrm{~km}$ altitude and two $\mathrm{O}_{3}$ features below: the subtropical filament on the south (at about 15:20 UTC) and the

\section{Stratospheric intrusions}

A. Carré et al.

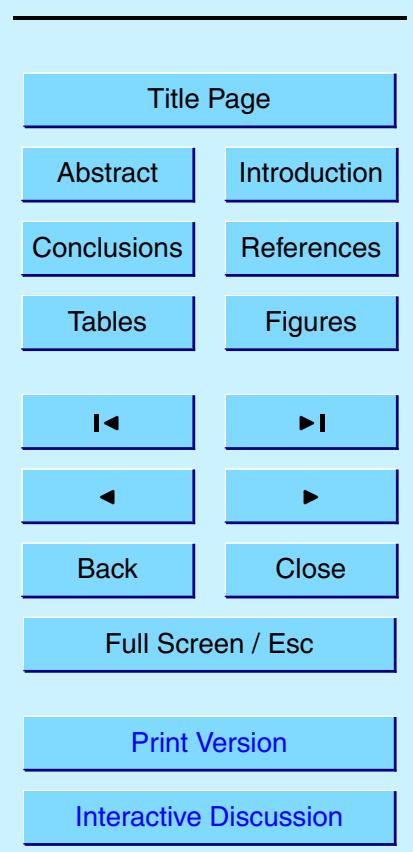

EGU 
ULTF on the north (at about 16:20 UTC) on both sides of the point J, which marks the change of direction along the air path (Fig. 2a). In that section, we only focus on the ULTF structure. High $\mathrm{O}_{3}$ concentrations characterize the intrusion, in excess of $120 \mathrm{ppbv}$ between 12 and $13 \mathrm{~km}$ altitude and in excess of $80 \mathrm{ppbv}$ at the flight level 5 (Fig. 3b). Unlike flight 40 (dicussed below), the flight 39 did not fly Northward enough to capture the joining of the ULTF to the lower stratosphere. Its joining is documented by Meso-NH vertical cross-sections (Figs. 5a and b) along the line "S-N" on Fig. 2a. The model reproduces the two stratospheric intrusions associated with the subtropical filament to the south and the ULTF to the north. It shows that the vertical structure of 10 the ULTF slopes downwards to the south. It confirms that the Lidar cross-section only captures the stratospheric intrusion below the tropopause at the southernmost tip of the ULTF. A comparison to the Lidar observations is possible between marks I and $\mathrm{J}$ (see the dashed white box). The underestimation of $\mathrm{O}_{3}$ concentrations of about $40 \mathrm{ppbv}$ between 12 and $13 \mathrm{~km}$, and the smoothing of the detailed ULTF vertical structure show 15 the inherent difficulties to perform detailled comparisons at the fine scales along the airpath.

The ULTF was again sampled about three hours later, during flight 40 (Figs. $2 \mathrm{~b}$ and 3c). During this flight, the in-situ $\mathrm{O}_{3}$ concentrations reached $90-100 \mathrm{ppbv}$ just before 19:00 UTC, over a distance of about $300 \mathrm{~km}$. As the aircraft followed a loop path the ULTF was probed again at the beginning of the landing of flight 40 at around 19:20 UTC, when $\mathrm{O}_{3}$ concentrations increased to $80 \mathrm{ppbv}$ (Fig. 3c). The vertical extension of the ULTF along the section marked "a-b" along flight 40 path (Fig. $2 b$ ) is described by Lidar $\mathrm{O}_{3}$ measurements, the Meso-NH-C O $\mathrm{O}_{3}$ field, the RDFPV field and ECMWF PV field (Fig. 6). The time-series of the $\mathrm{O}_{3}$ Lidar profile (Fig. 6a) clearly shows the subtropical tropopause (about $100 \mathrm{ppbv} \mathrm{O}_{3}$ ) at $14.5 \mathrm{~km}$ altitude going down to $13 \mathrm{~km}$. This section shows how the ULTF hangs below the tropopause and penetrates into the upper tropical troposphere down to below $12 \mathrm{~km}$, which is in agreement with the in-situ $100 \mathrm{ppbv}$ $\mathrm{O}_{3}$ maximum observed at the aircraft flight altitude. Nonetheless the Lidar measurements do not completly describe the vertical structure of the ULTF due to the presence
ACPD

5, 10301-10337, 2005

\section{Stratospheric intrusions}

A. Carré et al.

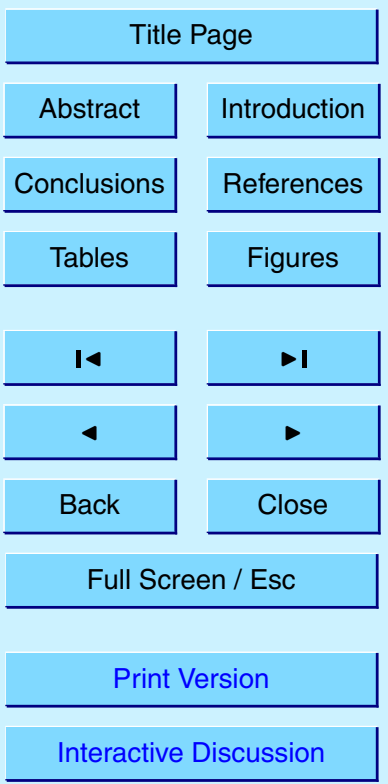

EGU 
of a cirrus after 19:00 UTC. An alternative vertical structure of the ULTF is offered by the RDFPV field (Fig. 6c). Ozone Lidar and RDFPV field are in good agreement and the RDFPV field nicely completes the view across the extratropical air mass. Because of the loop path of the aircraft the vertical structure is repeated again at the end of the 5 time series. Note that the PV field from the ECMWF analysis (Fig. 6c) only suggests the possibility of a stratospheric intrusion. $\mathrm{O}_{3}$ simulated by Meso-NH-C is plotted on Fig. 6b. Compared to the Lidar $\mathrm{O}_{3}$ and RDFPV fields, the ULTF simulated by Meso$\mathrm{NH}-\mathrm{C}$ is almost twice larger below $12.5 \mathrm{~km}$ altitude, and the $\mathrm{O}_{3}$ concentrations into the intrusion under $13 \mathrm{~km}$ are underestimated of about $30 \mathrm{ppbv}$. Further, Fig. $6 \mathrm{~b}$ confirms 10 (as evocated previously concerning flight 39), that the detailed vertical structure of the ULTF and the tropopause is smoothed in Meso- $\mathrm{NH} \mathrm{O}_{3}$ field. Coming back to the $\mathrm{O}_{3}$ in-situ comparaison along the aircraft path shown on Fig. 3c, the vertical cross-section (Fig. 6b) explains why $\mathrm{O}_{3}$ concentrations simulated along the flight 40 do not exhibit any tropospheric values of 40 ppbv after 19:00 UTC. Indeed, at the flight level (around $1512 \mathrm{~km}$ ), the aircraft in the model is not entering the upper troposphere before 19:15 UTC but is looping within the UTLF intrusion (see Fig. 2b). This underlines again the limit of the meso-scale simulation to document such high-resolution filaments, although it provides a more accurate view compared to the global ECMWF analysis.

A further description is given of the intrusion of the ULTF with in-situ $\mathrm{O}_{3}$ measure20 ments during the landing of flight 39 (Fig. 3b). During this landing across the southernmost tip of the upper-level trough (Fig. 2a), the in-situ $\mathrm{O}_{3}$ concentrations (Figs. $3 \mathrm{~b}$ and $7 \mathrm{c}$ ) increased abruptly, reaching more than $100 \mathrm{ppbv}$ between 10 and $8 \mathrm{~km}$ altitude. An example of Meso-NH 18-h backtrajectories initialized along the landing airpath of flight 39 at 18:00 UTC (i.e. the Meso-NH output that has the shortest time lag with aircraft 25 measurements) will be discussed now. The air parcel initialized on the $120 \mathrm{ppbv}$ ozone maximum (point $\mathrm{M}$ on Fig. 7c) is shown by a white cross in two vertical cross-sections (Figs. $7 \mathrm{a}$ and $\mathrm{b}$ ), the locations of which are shown on Figs. $1 \mathrm{c}$ and $2 \mathrm{~b}$, respectively. This air parcel is situated from 06:00 to 12:00 UTC on the western side of the upperlevel trough between 10 and $11 \mathrm{~km}$, as seen at 12:00 UTC on Fig. 7a. Note that this
ACPD

$5,10301-10337,2005$

\section{Stratospheric intrusions}

A. Carré et al.

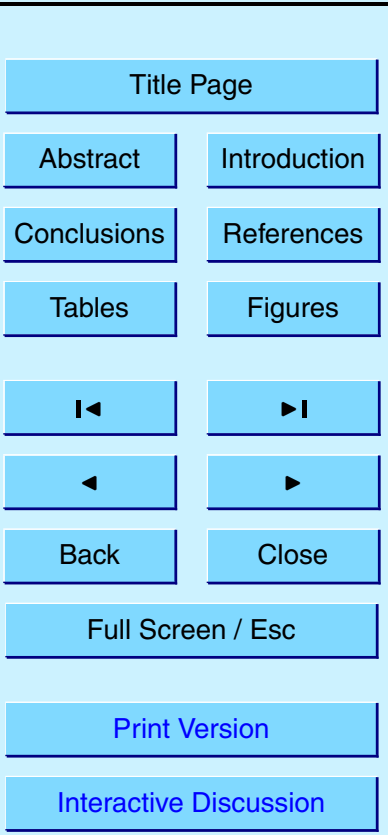

EGU 
air parcel leaved the simulation domain before 06:00 UTC. At 18:00 UTC (Fig. 7b) it is situated in the upper level stratospheric intrusion of the ULTF at about $10 \mathrm{~km}$. Thus, in this 12-hour period of time, the air parcel went down about $1 \mathrm{~km}$ along the $330 \mathrm{~K}$ isentropic surface with a practically perfect conservation of potential vorticity ( $P V \simeq 2.2 \mathrm{pvu}$ ). 5 Meanwhile, the time evolution of the potential vorticity structure (Figs. 7a and b) suggests that the air parcel comes from the stratospheric reservoir. The backtrajectory of this air parcel is representative of all other backtrajectories initialized at points of the vertical sounding (Fig. 7c) where the ozone concentration exceeds $80 \mathrm{ppbv}$ (not shown). The irreversible nature of the formation of this ULTF and its intrusion with 10 regard to STT is tested in Sect. 3.

After these descriptions of the stratospheric intrusions directly linked to the RWB at midlatitudes (tropopause fold, ULTF and its intrusion), we will focus now on the subtropical filament along the subtropical jet.

\subsection{Subtropical features}

15 At the end of the PICO3 campaign (Fig. 1d), the subtropical jet was characterized by a zonal state with a strong PV shear component on its cyclonic-shear side (Bell and Keyser, 1993). This zonal state resulted from the interaction between the RWB and the subtropical vortex core characterized by a strong PV curvature component (Figs. 1a-c). The subtropical vortex core was specially documented during flight 37 on 18 October 20 (Fig. 1a). Along the north-westward crossing of the vortex, in-situ ozone increases (Fig. 3a) during about $370 \mathrm{~km}$ from 45 to about $85 \mathrm{ppbv}$ just before the turn of the flight (Fig. 1a). The vertical extension of the vortex is given by the $\mathrm{O}_{3}$ Lidar measurements on Fig. 8a. It is compared to the vertical structure along the aircraft path of $\mathrm{PV}$ from ECMWF analyse on 18 October at 15:00 UTC (Fig. 8c) and of RDFPV (Fig. 8b). $\mathrm{O}_{3}$ 25 Lidar measurements at about $240 \mathrm{hPa}$ well join up with $\mathrm{O}_{3}$ in-situ measurements and show a relative maximum of $95 \mathrm{ppbv}$ in the subtropical vortex core. Interesting enough is the relative ozone minimum observed at about $200 \mathrm{hPa}$ that separates the structure of the subtropical vortex core observed below from the stratosphere above. Such a
ACPD

5, 10301-10337, 2005

\section{Stratospheric intrusions}

A. Carré et al.

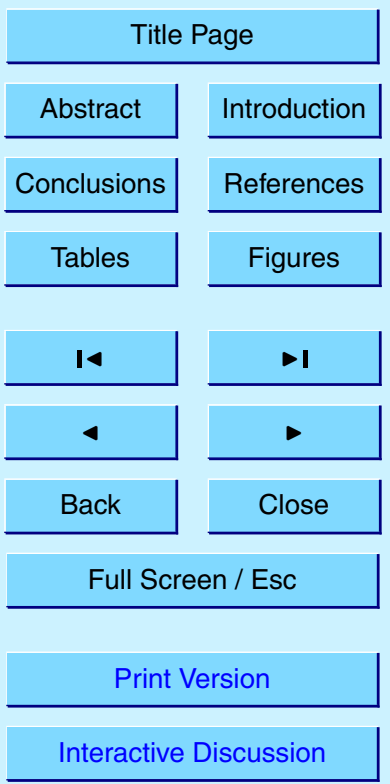

EGU 
mesoscale disruption of the tropopause is totally missed by the ECMWF PV structure (Fig. 8c). The comparison also shows that ECMWF data put the subtropical vortex core a bit too much on the southeast, so that the aircraft airpath may have been a few tens kilometers too short to enter the centre of the subtropical vortex and has likely 5 sampled its eastern side. The RDFPV structure along the aircraft path (Fig. 8b) allows a more accurate comparison with $\mathrm{O}_{3}$ Lidar observations in the sense that an outline of the separation of the vortex core from the stratosphere is reconstructed from the Lagrangian technique. To go further on the dynamics associated with the mesoscale disruption of the tropopause above the subtropical vortex, the vertical structure of the 10 subtropical vortex is examined in a longer zonal cross-section (noted T0, see location on Fig. 1a). The PV structure (Fig. 8e) confirms the smooth topography of the tropopause across the subtropical jet on the left part and across the subtropical vortex just right of the center. The RDFPV structure (Fig. 8d) shows that the disruption of the tropopause above the subtropical vortex comes from a tropospheric intrusion that went up on the western side and that is transported southward round the vortex to the eastern side where it is observed by the aircraft. Individual air parcel backtrajectories (not shown) indicate that the source of the tropospheric intrusion that surmounts the subtropical vortex is the upper troposphere just north of the vortex. The observation of this tropospheric intrusion fitting between the subtropical jet and the subtropical vortex indicates that the two previous features are two separate dynamical entities and that the subtropical vortex is an ageing structure coming off the stratospheric reservoir. It implicitly shows that all air parcels within the subtropical vortex are subject to STT.

Flight 39 flew through the subtropical vortex core evolving towards a filament on 20 October (Fig. 1c and 2a). The in-situ $\mathrm{O}_{3}$ concentrations (Fig. 3b) characterise this structure between about 15:05 UTC and 15:35 UTC with values around $60 \mathrm{ppbv}$. Meso-NH-C also captures this feature, though the $\mathrm{O}_{3}$ modeled concentration is overestimated. This demonstrates a crossing into the filament over a distance of about $450 \mathrm{~km}$. The vertical structure of this subtropical filament in the Meso-NH vertical cross section (Fig. 5) shows a stratospheric intrusion (on the left side) penetrating into the
ACPD

$5,10301-10337,2005$

\section{Stratospheric intrusions}

A. Carré et al.

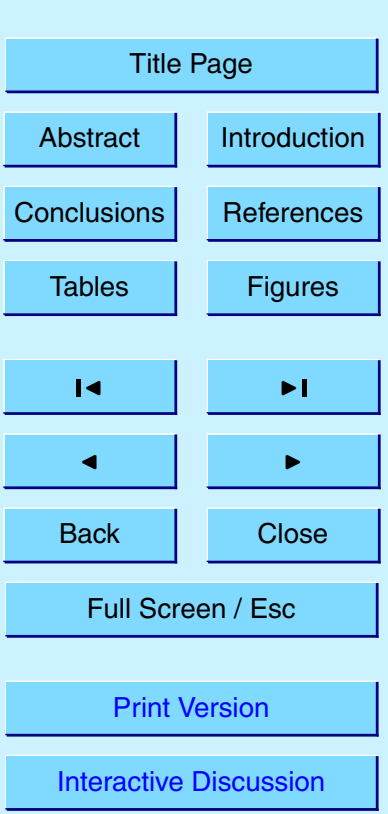

EGU 
troposphere down to $8 \mathrm{~km}$ in altitude, with air characterised by modeled ozone concentrations $\geq 65 \mathrm{ppbv}$ and $\mathrm{PV}$ value $\geq 1.5 \mathrm{pvu}$. The vertical structure of the subtropical filament in the Lidar times series (Fig. 5c) confirms that the latter has finally been rooted out of the stratospheric reservoir, as already inferred from $\mathrm{O}_{3}$ Lidar observations during 5 flight 37 (Fig. 8a). Meso-NH being initialized with the coarse structure of the subtropical vortex that does not include the tropospheric intrusion (compare Figs. 8d and e), the process to root out the subtropical filament from the stratosphere can not be simulated. This time, the RDF technique also failed to reproduce the extraction of the subtropical filament (not shown) because of a too large integration time ( $\geq 3$ days) to recover the 10 tropospheric intrusion captured on Fig. 8d. Such a failure will hamper the reconstruction of PV along the flight 41 as far as the upper level part of the subtropical filament is concerned.

On 21 October, both the ULTF and the subtropical filament came closer together as the first feature moved south-eastward and the second one extended eastward. 15 Such a deformation can be seen on the evolution of the ECMWF PV fields (Fig. 1) and of Meso-NH PV fields (Fig. 2). In-situ $\mathrm{O}_{3}$ measurements during flight 41 (Fig. 3d) document the joining of the 2 filaments with a southward in-bound and a northward out-bound time series across the two features. The nearly identical in-bound and outbound flight paths (Figs. 2c, 3d) explain the symmetrical shape of the in-situ $\mathrm{O}_{3}$ measurements. The aircraft sampled the ULTF (100 ppbv between 08:10 and 08:20 UTC) and the subtropical filament (60 ppbv between 08:20 and 08:35 UTC) with only a short passage in tropospheric air in between. In comparison, flight 39, which flew through the subtropical filament and the ULTF one day earlier, sampled tropospheric air $\left(\mathrm{O}_{3}\right.$ value around $40 \mathrm{ppbv}$ ) during about $375 \mathrm{~km}$ between these two structures (Fig. 3b). 25 Therefore, it turns out that the Rossby wave breaking comes with a meridional contraction and a zonal stretching of conservative parameters (PV, ozone) in the subtropical region. It is noticeable that the time response of the ozone instrument is short enough to still distinguish the two features on flight 41 , indicating that mixing processes had not yet smoothed the strong ozone gradients forced by large horizontal shears during the
ACPD

5, 10301-10337, 2005

\section{Stratospheric intrusions}

A. Carré et al.

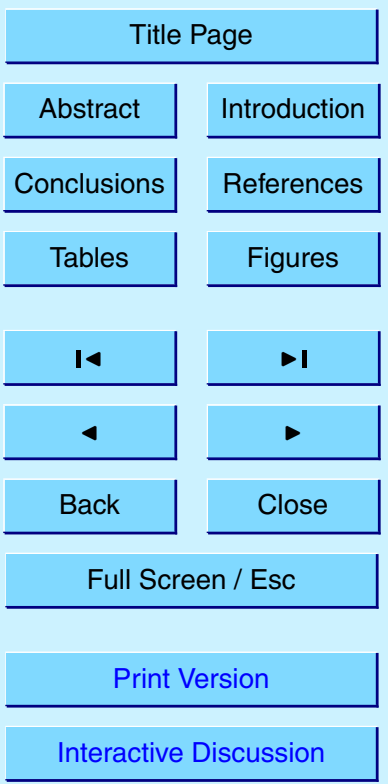

EGU 
zonal stretching.

Figure 9 presents a comparison along the northward out-bound part of flight 41 (between marks 1 and 2 shown on Fig. 2c) between the ozone Lidar vertical profile time series (graph a) and Meso-NH-C vertical cross-sections of PV (graph b) and ozone 5 (graph c), and with ECMWF vertical cross-sections of PV (graph d) and RDFPV (graph e). Lidar $\mathrm{O}_{3}$ measurements are presented all along the flight (hence the symmetrical shape of the ozone field), but we focus only on the second part between marks 1-2 to compare with other graphs. Even averaged at the time resolution of the Lidar measurements, ozone in-situ measurements (bottom coloured line on graph a) still show 10 the crossing of the subtropical filament (between 08:48 and 08:54 UTC) followed by the crossing of the ULTF (at 09:00 UTC). Although the interruptions of measurements and the presence of aerosol put a strain on the continuity of Lidar measurements, combining the north- and southward outbounds of the flight lead to the statement that the ULTF observed at the in-situ level slopes northwards up to the tropopause level at about $14.5 \mathrm{~km}$ altitude, giving it a vertical depth of about $4 \mathrm{~km}$. The time resolution of the Lidar does not allow to clearly separate the ULTF from the subtropical filament (as done by the in-situ instrument), but again, the vertical resolution of the Lidar confirms that the subtropical filament is rooted of the stratosphere.

Both Meso-NH-C (Fig. 9c) and the RDF technique (Fig. 9e) succeed to coarsly reproduce the vertical structure of the ULTF, yet with an advantage of the RDF PV as far as the tip of tropospheric air stuck between the ULTF and the subtropical filament is concerned. Both of the two tools also suggest the presence of the subtropical filament at flight level, but neither of the two shows its extraction of the stratospheric reservoir.

To conclude, we show in that section that the numerous stratospheric intrusions sampled during the PICO3 campaign are filamentary structures associated to the RWB linked to the upper-level trough and to an ageing subtropical vortex. Meso-NH simulations, ECMWF analyses and RDF technique complete the in-situ and Lidar $\mathrm{O}_{3}$ measurements to document their 2-D structures in horizontal or vertical view. We show the ability of Meso-NH simulations to reproduce these filamentary structures and the con-

\section{ACPD}

5, 10301-10337, 2005

\section{Stratospheric intrusions}

A. Carré et al.

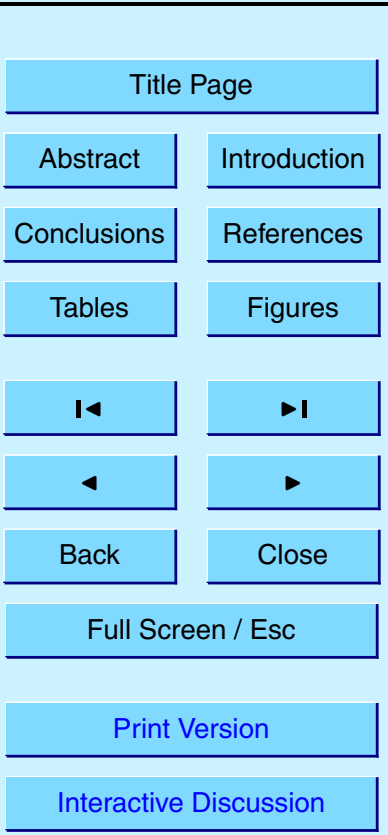

EGU 
tribution of the RDF technique to provide a better high-resolution stratospheric tracer field to describe the fine resolution of such filaments, as long as integration time is not too large.

\section{Reversibility of stratosphere-troposphere transport}

5 We focus here on the STT associated to each stratospheric structure highlighted in the previous section. The method is based on the use of the Lagrangien tracers available in Meso-NH simulations and developed by Gheusi and Stein (2002). We already have presented results from Meso-NH backward trajectories, but this Lagrangian tool also permit to perform forward trajectories. In that case, Meso-NH trajectories track the 10 evolution of a set of Lagrangian parcels that are initially in a 3-D box at a time taken as the "initial" time. It gives also the ability to track the evolution of fields like $\mathrm{PV}, \mathrm{O}_{3}$ ... for the parcels situated at the top of the plume. The Lagrangian technique used in Meso-NH is based on Eulerian passive tracers which are the initial coordinates (determined at an arbitrary initial time) of air parcels. These initial coordinates are passive 15 scalars driven by the flow: their evolution is governed by the advection equation. But as the advection equation is dicretized into finite elements, it implies that the passive tracer fields experience not only advection (as is the case for LAGRANTO trajectories from ECMWF), but also sub-grid turbulent and convective transports through the corresponding parametrizations in Meso- $\mathrm{NH}$. Sub-grid turbulence is parametrized with a 20 1-D, 1.5-order scheme using the turbulent kinetic energy as a prognostic value (Cuxart et al., 2000); subgrid convection is parametrized with a 1-D mass flux sheme (Bechtold et al., 2001). This method provides a response to the limitations of the LAGRANTO trajectories calculated from ECMWF analyses, due to the absence of sub-grid transport parametrization in the trajectory computation and from time and space interpolations
ACPD

5, 10301-10337, 2005

\section{Stratospheric intrusions}

A. Carré et al.

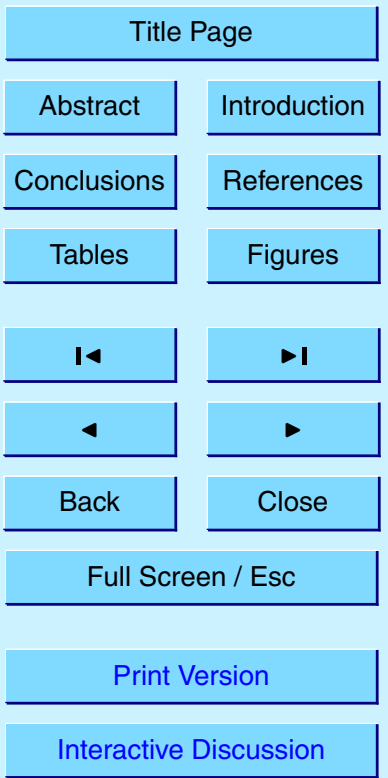

EGU 
In the previous section, we saw from the Meso-NH simulations (backward trajectories) as well as the RDF results, that ozone maxima recorded during flight 40 take-off had a stratospheric origin through a tropopause folding process. In favour of the irreversibility

5 of the STT of these air parcels are forward trajectories (not shown) that demonstrated that no dynamic agent was available to make them re-integrate the lower stratosphere after they had subsided $7 \mathrm{~km}$ beneath the subtropical tropopause. At the time of the observation, their residence time in the troposphere exceeded $12 \mathrm{~h}$, which, according to James et al. (2003b), is a threshold beyond which irreversible transport impacts on the tropospheric ozone budget and upper-troposheric chemistry.

It was clear from the Lidar observations shown at the previous section that the subtropical filament has been irreversibly extracted from the stratosphere: the rooted filament intrusion is observed at flight 37,39 and 41 , thus during 4 consecutive days. Considering these flight paths (Fig. 1), it illustrates also its eastward streching dur15 ing the filamentary process associated to the strongest zonal state of the subtropical jet during this period. Meso-NH forward trajectories (not shown) confirm that the air parcels of the subtropical filament are subject to irreversible STT.

\subsection{Upper-level trough filament and its intrusion}

The ULTF was sampled during PICO3 flights 39,40 and 41 at cruising altitude. For

each flight, the associated ozone concentration was higher than $80 \mathrm{ppbv}$. To focus on the fate of these ozone-rich air parcels with regard to the STT, we used Meso-NH forward trajectories.

The localisation of a box $F$ that captures ozone-rich air parcels of the ULTF observed during flight 39 is shown on Fig. 10. For convenience, the plume of air parcels in that about $200 \mathrm{~km} \times 100 \mathrm{~km}$ and a vertical extension of $1.7 \mathrm{~km}$. It emerges from the time evolution (Fig. 11) that air parcels in box $F$ have two distinct types of behaviour: i) plume

\section{Stratospheric intrusions}

A. Carré et al.

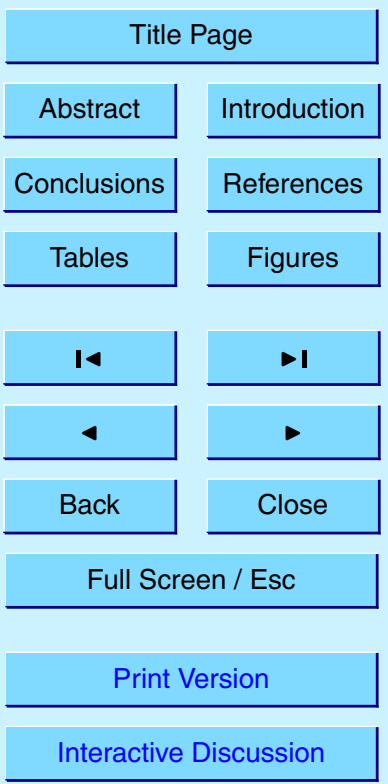

EGU 
$1 \mathrm{~F}$ seen along the Sect. 1 (graph c) moves southward and spreads in the zonal direction, while ii) plume $2 \mathrm{~F}$ seen along the section 2 (graph $\mathrm{d}$ ) moves southeastward and spreads in the meridional direction. The western part of plume $1 \mathrm{~F}$ is embedded in the anticyclonic circulation (so moves westward) and the eastern part is embedded in the 5 polar jet circulation. Such a deformation by the large scale wind field can be detected on the PV evolution (Figs. 1c and d), and is directly associated with the Rossby Wave Breaking. These particles, along Sect. 1 (Fig. 11c and d), were situated well under the tropopause level at $2 \mathrm{pvu}$, around $11.8 \mathrm{~km}$ (Fig. 11d, dashed pink line) on 21 October. They subsided by at least $1.5 \mathrm{~km}$ on 21 October (Figs. 11d and f), and the farther west10 ward they were situated, the earlier the subsidence began (see the diagonal shape of the left side of the plume on graphs $b, d, f)$. This movement is accompanied by $a$ loss of modeled $\mathrm{O}_{3}$ concentration (at least for the top of the plume), which reaches 40 ppbv on 21 October at 03:00 UTC, and also by a loss of PV which varies between 0 and $0.4 \mathrm{pvu}$ at this date (not shown). These elements indicate an irreversible transport 15 over a significant time (more than twenty hours) certainly associated with a mixing of tropospheric air.

For plume 2F, we observe fast transport of air parcels embedded in the polar jet. Air parcels were situated over Spain on 21 October at 09:00 UTC (Fig. 11e). During this transport, concentrations of $\mathrm{O}_{3}$ (about $70 \mathrm{ppbv}$ ) tend to be conserved, as do PV values (about $1.5 \mathrm{pvu}$, not shown). The Sect. 2 (Fig. 11f) is situated along plume 2F, elongated meridionally around the Greenwich meridian. We observe that air parcels stay at about the same altitude and are situated below or above the tropopause at $2 \mathrm{pvu}$ around $11.8 \mathrm{~km}$. The bottom part of plume $2 \mathrm{~F}$, situated around $11 \mathrm{~km}$, is made of air parcels clearly situated in the upper troposphere, where PV values are less than $251 \mathrm{pvu}$ (not shown). It highlights an irreversible transport of stratospheric air into the troposphere, with air parcels transported into the troposphere from the ULTF over a period of $21 \mathrm{~h}$ from 20 October 12:00 UTC to 21 October 09:00 UTC.

For air parcels of plume $2 \mathrm{~F}$ that are situated around $11.8 \mathrm{~km}$, irreversible transport is not demonstrated. In fact, the upper part of this plume is situated just around the $2 \mathrm{pvu}$
ACPD

5, 10301-10337, 2005

\section{Stratospheric intrusions}

A. Carré et al.

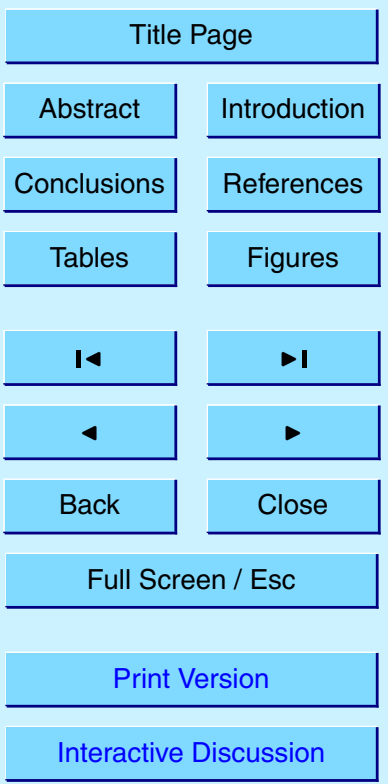

EGU 
isoline, with PV values between 1.2 and $2.4 \mathrm{pvu}$. For these air parcels, initially situated in the southern part of the ULTF, a possible return into the stratosphere may occur later on.

Thus, even if a reversible transport may occured, we see that a major part of the 5 ULTF presents an irreversible transport from the stratosphere to the troposphere.

Discussing the intrusion of the ULTF into the troposphere (Figs. 5 and 7), we have seen that the intrusion descends as low as $8 \mathrm{~km}$ altitude, as observed during the landing of flight 39 (Fig. 7c). We investigated the time evolution of this stratospheric intrusion by computing Meso-NH forward plumes from a 3-D box situated in the intrusion 10 on 20 October at 12:00 UTC. We chose a box extending from 8.6 to $9.6 \mathrm{~km}$. For the sake of brevity, we do not show the corresponding plots because the method is the same as for the previous section. The forward plume shows a transport at the local scale for this intrusion until 21 October, 09:00 UTC. Air parcels stay in the vicinity of the Canary Islands. The plume evolves with a slight anticyclonic movement, a mean 15 PV decreasing to $0.4 \mathrm{pvu}$ and a descent into the upper troposphere about $1 \mathrm{~km}$ deep. It is concluded that the intrusion of the ULTF is irreversible and acts as a source for the ozone budget in the upper troposphere.

\section{Conclusions}

This study analysed in-situ and Lidar observations of the airborne PICO3 campaign

over the Canary Islands during a mid-latitude Rossby wave-breaking and its interaction with the subtropical jet. PICO3 campaign succeeds to capture high-resolution stratospheric-origin filament structures and several events of stratosphere-troposphere transport have been examined. The series of 4 flights analysed involves i) a tropopause folding process, ii) the filamentation of the upper-level trough consecutive to the Rossby wave-breaking event, iii) the further deep tropospheric intrusion of the latter filamentary structure, and iv) the evolution along the subtropical jet of a subtropical vortex core towards a subtropical filament under the large scale deformation effect of the

ACPD

5, 10301-10337, 2005

\section{Stratospheric} intrusions

A. Carré et al.

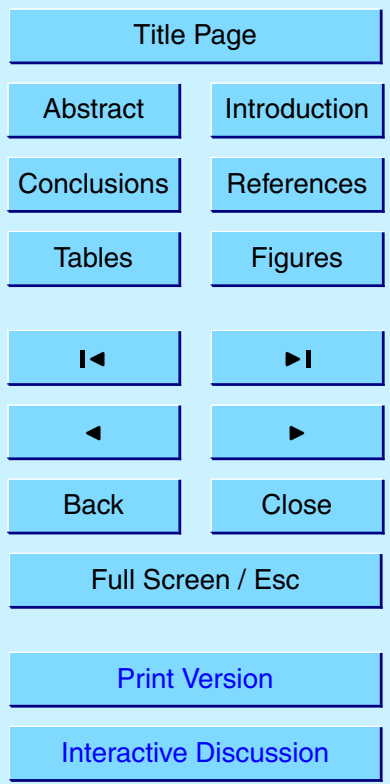

EGU 
Rossby wave-breaking. To investigate the three-dimensional fine scale structure of all structures we have used two numerical models. Anomalously high tropospheric ozone in-situ and Lidar observations were interpreted by reconstruction of the fine scale structures in potential vorticity using the Reverse Domain Filling (RDF) technique applied to 5 ECMWF analyses. The RDF technique is particularly suitable to capture the potential vorticity signatures associated with STE. The comparison of the model results using a stratospheric tracer and online chemistry with ozone in-situ observations indicate that the model is crudely consistent with the filamentary structures found. We show that the RDF technique complete these data with the stratospheric tracer finest scale showing 10 the best agreement with observations.

We took advantage of the Meso-NH simulation to document the irreversible nature of the stratosphere-troposphere transport of air parcels involved in filaments. Modelled internal backward and forward trajectory calculations show totally irreversible transport for the tropopause fold and the tropospheric intrusion of the upper-level trough filament, and major irreversible transport for the upper-level trough. The subtropical filament presents also totally irreversible transport, as directly demonstrated by the $\mathrm{O}_{3}$ Lidar measurements. A large impact of filamentary structures left behind a Rossby wavebreaking on to the budget of the upper-level tropospheric ozone in the subtropics can be anticipated from our results.

20 Acknowledgements. The authors would like to thank IDRIS for allocating computer ressources, Meteo-France for providing MOCAGE analysis initializing Meso-NH-C, INSU-DT and IGN for the airborne infrastructures, and ECMWF for providing the analyses. Also, we thank $\mathrm{C}$. Mari for helping in Meso-NH simulations and J.-P. Chaboureau, P. Nédélec and R. Scott for assisting in the operation of the campaign. We express our appreciation to the Mystere 20 flight crew for 25 their dedication in making PICO3 observations.
ACPD

5, 10301-10337, 2005

\section{Stratospheric intrusions}

A. Carré et al.

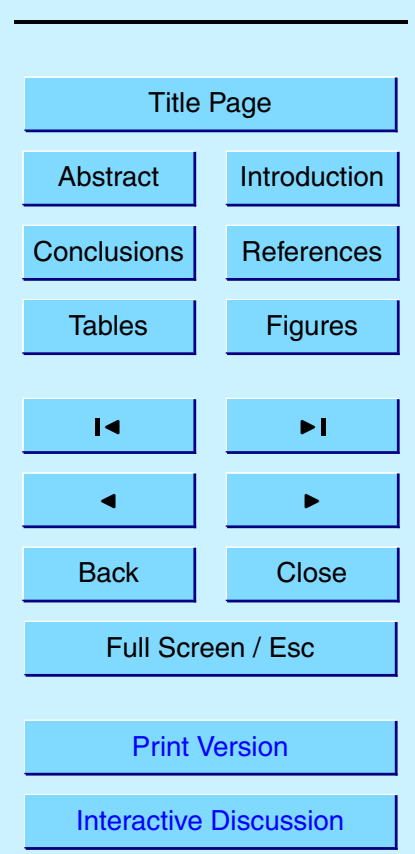

EGU 


\section{References}

Ancellet, G. and Ravetta, F.: Compact airborne lidar for tropospheric ozone (ALTO): description and field measurements, Appl. Opt., 37, 5509-5521, 1998.

Appenzeller, C., Holton, J. R., and Norton, W. A.: Fragmentations of stratospheric intrusions, J.

5 Geophys. Res., 101, 1435-1456, 1996a.

Baray, J.-L., Baldy, S., Diab, R. D., and Cammas, J.-P.: Dynamical study of a tropical cut-off low over South Africa and its impact on tropospheric ozone, Atmos. Environ., 37, 1475-1488, 2003.

Bechtold, P., Kain, J., Bazile, E., Mascart, P., and Richard, E.: A mass flux convection scheme for regional and global models, Quart. J. Roy. Meteor. Soc., 127, 869-886, 2001.

Bell, G. D., and Keyser, D.: Shear and curvature vorticity and potential-vorticity interchanges: Interpretation and application to a cutoff cyclone event, Mon. Wea. Rev., 121, 76-102, 1993.

Crassier, V., Suhre, K., Tulet, P., and Rosset, R.: Development of a reduced chemical scheme for use in mesoscale meteorological models, Atmos. Environ., 34, 2633-2644, 2000.

15 Crutzen, P., Lawrence, M., and Pöschl, U.: On the background photo chemistry of tropospheric ozone, Tellus, 51, 123-146, 1999.

Cuxart, J., Bougeault, P., and Redelsperger, J.-L.: A turbulence scheme allowing for mesoscale and large-eddy simulations, Quart. J. Roy. Meteor. Soc., 126, 1-30, 2000.

Danielsen, E. F.: Stratospheric-tropospheric exchange based on radioactivited, ozone and potential vorticity, J. Atmos. Sci., 25, 502-518, 1968.

Gheusi, F. and Stein, J.: Lagrangian description of air-flows using Eulerian passive tracers, Quart. J. Roy. Meteor. Soc., 128, 337-360, 2002.

Gouget, H., Vaughan, G., Marenco, A., and Smit, H. G. J.: Decay of a cut-off low and contribution to stratosphere-troposphere exchange, Quart. J. Roy. Meteor. Soc., 126, 1117-1141, 2000.

Hauglustaine, D. A., Brasseur, G. P., Waters, S., Rasch, P. J., Muller, J.-F., Emons, L. K., and Carroll, M. A.: MOZART, a global chemical transport model for ozone and related chemical tracers, Part 2: Model results and evaluation, J. Geophys. Res., 103, 28 291-28 335, 1998.

Hegglin, M. I., Brunner, D., Wernli, H., Schwierz, C., Martius, O., Hoors, P., Fisher, H., Spelten, N., Schiller, C., Krebsbach, M., Parchatka, U., Weers, U., Staehelin, J., and Peter, T.: Tracing troposphere-to-stratosphere transport above a mid-latitude deep convective system, Atmos. Chem. Phys. Discuss., 4, 169-206, 2004,
ACPD

5, 10301-10337, 2005

\section{Stratospheric intrusions}

A. Carré et al.

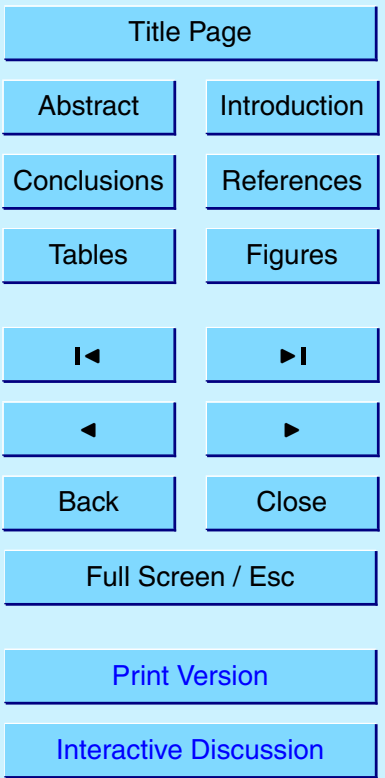

EGU 
SRef-ID: 1680-7375/acpd/2004-4-169.

Hoerling, M. P., Schaack, T. K., and Lenzen, A. J.: Global objective tropopause analysis, Mon. Wea. Rev., 119, 1816-1831, 1991.

Holton, J. R., Haynes, P. H., McIntyre, M. E., Douglass, A. R., Rood, R. B., and Pfister, L.: Stratosphere-Troposphere Exchange, Reviews of Geophysics, 33, 403-439, 1995.

Hoskins, B. J., Mclntyre, M. E., and Robertson, A. W.: On the use and significance of isentropic potential vorticity maps, Quart. J. Roy. Meteor. Soc., 111, 877-946, 1985.

James, P., Stohl, A., Forster, C., Eckhardt, S., Seibert, P., and Frank, A.: A 15-year climatology of stratosphere-troposphere exchange with a Lagrangian particle dispersion model: 1 , Methodology and validation, J. Geophys. Res., 108(D12), 8519, doi:10.1029/2002JD002637, 2003a.

James, P., Stohl, A., Forster, C., Eckhardt, S., Seibert, P., and Frank, A.: A 15-year climatology of stratosphere-troposphere exchange with a Lagrangian particle dispersion model: 2, Mean climate and seasonal variability, J. Geophys. Res., 108(D12), 8522, doi:10.1029/2002JD002639, 2003b.

Keyser D. and Shapiro, M. A.: A review of the structure of upper-level frontal zones, Mon. Wea. Rev., 114, 452-499, 1986.

Lafore, J. P., Stein, J., Asencio, N., Bougeault, P., Ducrocq, V., Duron, J., Fischer, C., Héreil, P., Mascart, P., Masson, V., Pinty, J. P., Redelsperger, J. L., Richard, E., and Vilà-Guerau de Arellano, J.: The Meso-NH Atmospheric Simulation System, Part I: adiabatic formulation and control simulations, Ann. Geophys., 16, 90-109, 1998,

SRef-ID: 1432-0576/ag/1998-16-90.

Marenco, A., Thouret, V., Nédélec, P., Smit, H., Helten, G. M., Kley, D., Karcher, F., Simon, P., Law, K., Pyle, J., Poschmann, G., Von Wrede, R., Hume, C., and Cook, T.: Measurement of ozone and water vapour by Airbus in-service aircraft : The MOZAIC airborne program, an overview, J. Geophys. Res., 103, 25631-25642, 1998.

Morcrette, J.-J.: Radiation and cloud radiative properties in the European Center for Medium range Weather Forcasts operational weather forecast system, J. Geophys. Res., 96, 91219132, 1991.

30 Postel, G. A. and Hitchman, M. H.: A climatology of Rossby wave breaking along the subtropical tropopause, J. Atmos. Sci., 56, 359-373, 1999.

Scott, R. K., Cammas, J.-P., Mascart, P., and Stolle, C.: Stratospheric filamentation into the upper tropical troposphere, J. Geophys. Res., D106, 11 835-11 848, 2001.

\section{ACPD}

5, 10301-10337, 2005

\section{Stratospheric intrusions}

A. Carré et al.

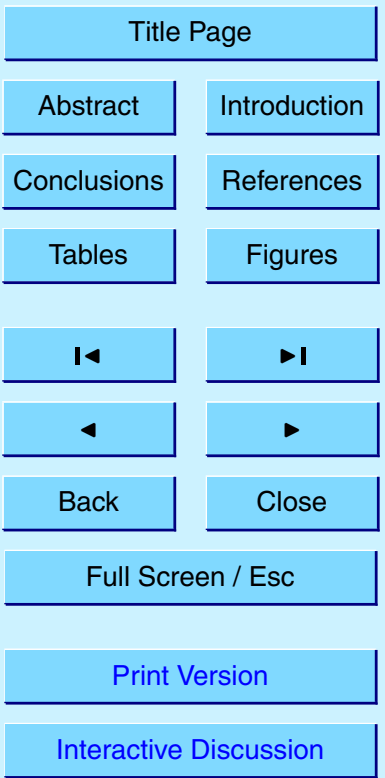

EGU 
Schoeberl, M. R. and Newman, P. A.: A multiple-level trajectory analysis of vortex filaments, J. Geophys. Res., 100, 25801-25815, 1995.

ACPD

Sprenger, M., Croci Maspoli, M., and Wernli, H.: Tropopause folds and cross-tropopause transport: A global investigation based upon ECMWF analyses for the time period March 2000 to February 2001, J. Geophys. Res., 108(D12), 8518, doi:10.1029/2002JD002587, 2003.

Stohl, A.: A 1-year Lagrangian climatology of airstreams in the Northern Hemisphere troposphere and lowermost stratosphere, J. Geophys. Res., 106, 7263-7279, 2001.

Sutton, R., Maclean, H., Swinbank, R., O'Neill, A., and Taylor, F. W.: High-resolution stratospheric tracer fields estimated from satellite observations using lagrangian trajectory calculations, J. Atmos. Sci., 51, 2995-3005, 1994.

Thorncroft, C. D., Hoskins, B. J., and Mclntyre, M. E.: Two paradigms of baroclinic-wave life cycle behaviour, Quart. J. Roy. Meteor. Soc., 119, 17-55, 1993.

Waugh, D. W. and Polvani, L. M.: Climatology of intrusions into the tropical upper troposphere, Geophys. Res. Lett., 27, 3857-3860, 2000.

Wei, M.-Y: A new formulation of the exchange of mass and trace constituents between the stratosphere and troposphere, J. Atmos. Sci., 44, 3079-3086, 1987.

Wernli, H. and Bourqui, M.: A Lagrangian 1-year climatology of (deep) cross-tropopause exchange in the extratropical Northern Hemisphere, J. Geophys. Res., 107(D2), 4021, doi:10.1029/2001JD000812, 2002.

Wernli, H. and Davies, H. C.: A Lagrangian-based analysis of extratropical cyclones, I, The method and some applications, Quart. J. Roy. Meteor. Soc., 123, 467-489, 1997.

Wirth, V. and Egger, J.: Diagnosing extratropical synoptic-scale stratosphere-troposphere exchange: A case study, Quart. J. Roy. Meteor. Soc., 126, 635-656, 1999.

\section{Stratospheric intrusions}

A. Carré et al.

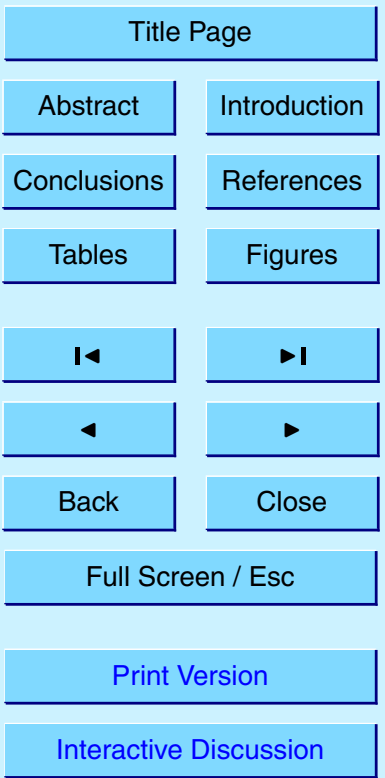

EGU 


\section{ACPD}

$5,10301-10337,2005$

\section{Stratospheric intrusions}

A. Carré et al.

Table 1. Occurrence of PICO3 flights and associated stratospheric structures sampled.

\begin{tabular}{|c|c|c|c|}
\hline Date & 18 Oct. 2000 & 20 Oct. 2000 & 21 Oct. 2000 \\
\hline $\begin{array}{l}\text { Flight and } \\
\text { Hours }\end{array}$ & $37(13: 00$ to $16: 00$ UTC) & $\begin{array}{l}39(14: 15 \text { to } 17: 00 \text { UTC) } \\
40(18: 00 \text { to } 19: 30 \text { UTC) }\end{array}$ & 41 (07:15 to 09:45 UTC) \\
\hline $\begin{array}{l}\text { Stratospheric } \\
\text { structures }\end{array}$ & subtropical vortex & $\begin{array}{l}\text { trough and subtropical filaments (39) } \\
\text { trough filament and tropopause fold (40) }\end{array}$ & trough and subtropical filaments \\
\hline
\end{tabular}

\begin{tabular}{|c|c|}
\hline \multicolumn{2}{|c|}{ Title Page } \\
\hline Abstract & Introduction \\
\hline Conclusions & References \\
\hline Tables & Figures \\
\hline 14 & $\triangleright 1$ \\
\hline 4 & - \\
\hline Back & Close \\
\hline \multicolumn{2}{|c|}{ Full Screen / Esc } \\
\hline Print & rsion \\
\hline
\end{tabular}

EGU 

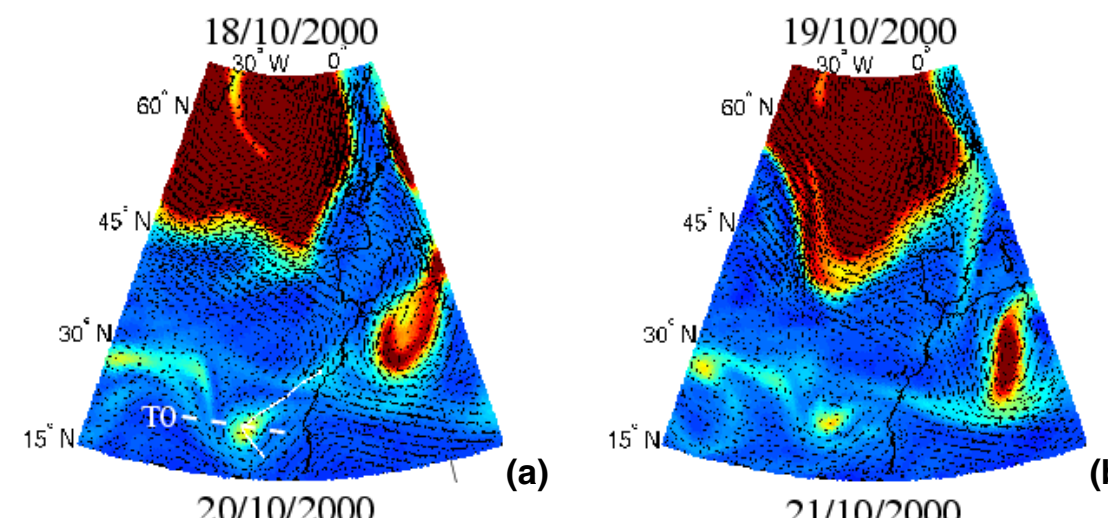

ACPD
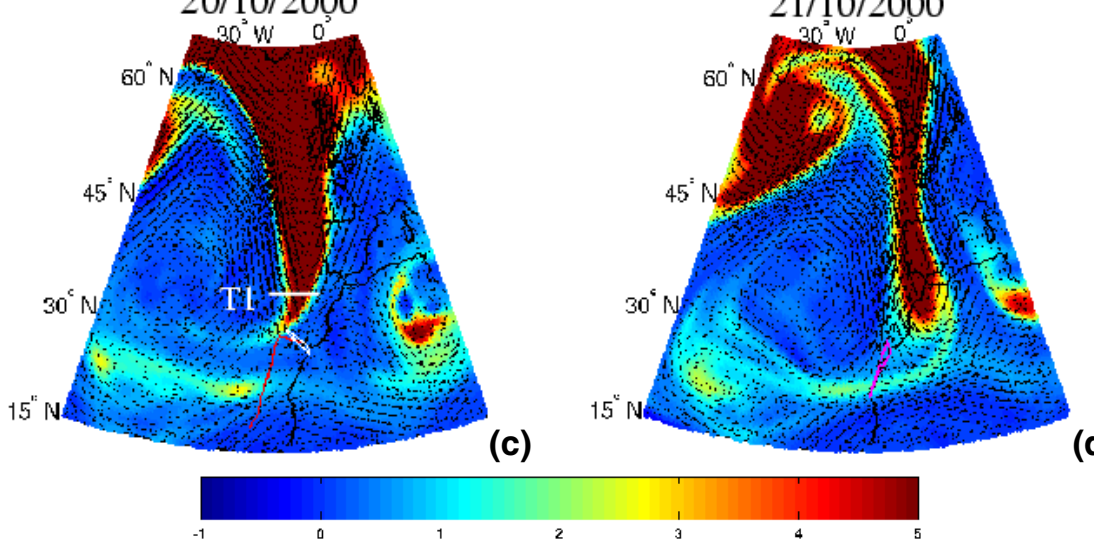

(b)

5, 10301-10337, 2005

\section{Stratospheric intrusions}

A. Carré et al.

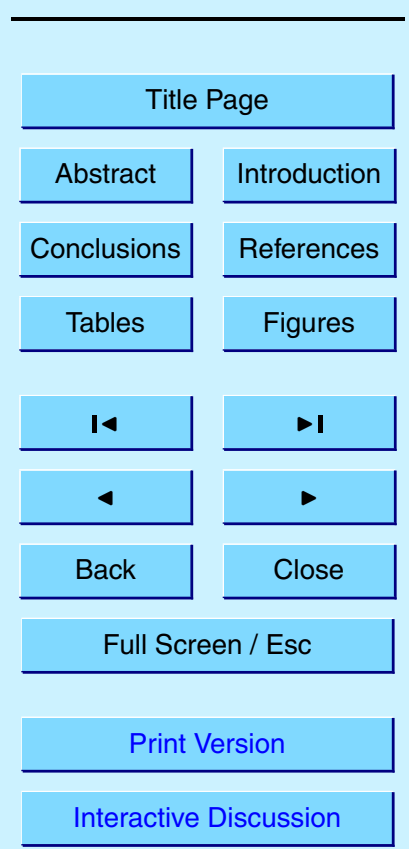

Fig. 1. ECMWF analyses at 12:00 UTC from 18 October (a) to 21 October 2000 (d): evolution of $\mathrm{PV}$ distribution (pvu) at $250 \mathrm{hPa}$ with the horizontal wind vectors superposed (largest vectors indicate a horizontal wind of about $70 \mathrm{~m} / \mathrm{s}$ ). The trajectory of flight 37 is indicated on the $18 \mathrm{Oc}-$ tober picture (white line, graph a), as are the paths of flights 39 (in red) and 40 (in white) on the 20 October graph (c), and the path of flight 41 (in dark pink) on the 21 October graph (d). White lines on gaphs (a) and (c) represent the location of cross sections noted T0 and T1 wich will be discussed in next sections. 


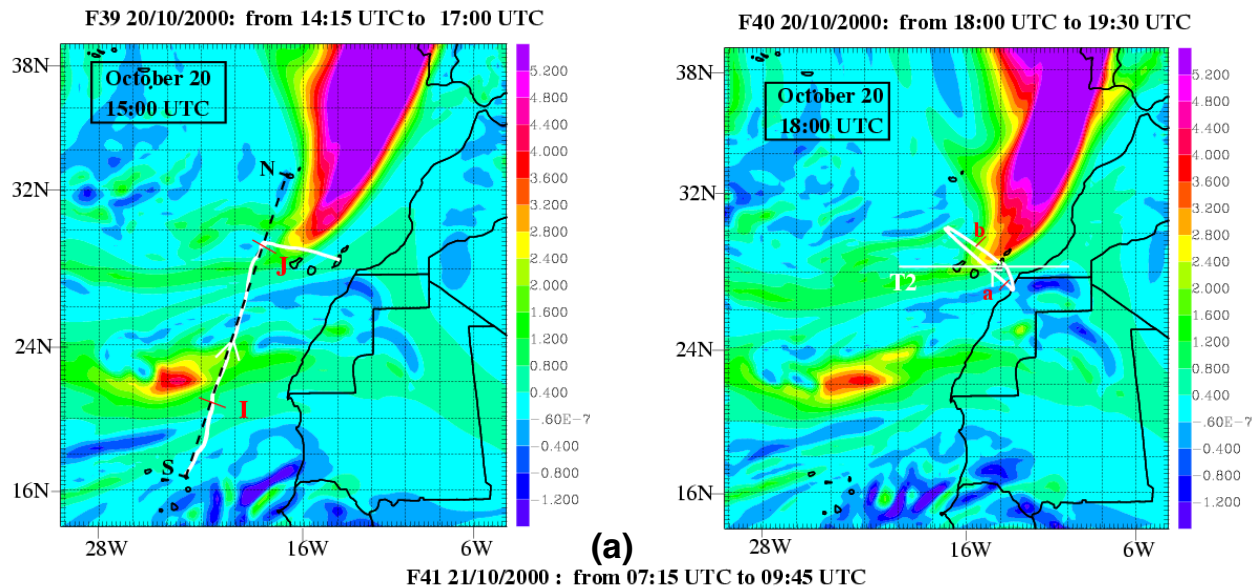

(b)

ACPD

$5,10301-10337,2005$

\section{Stratospheric intrusions}

A. Carré et al.
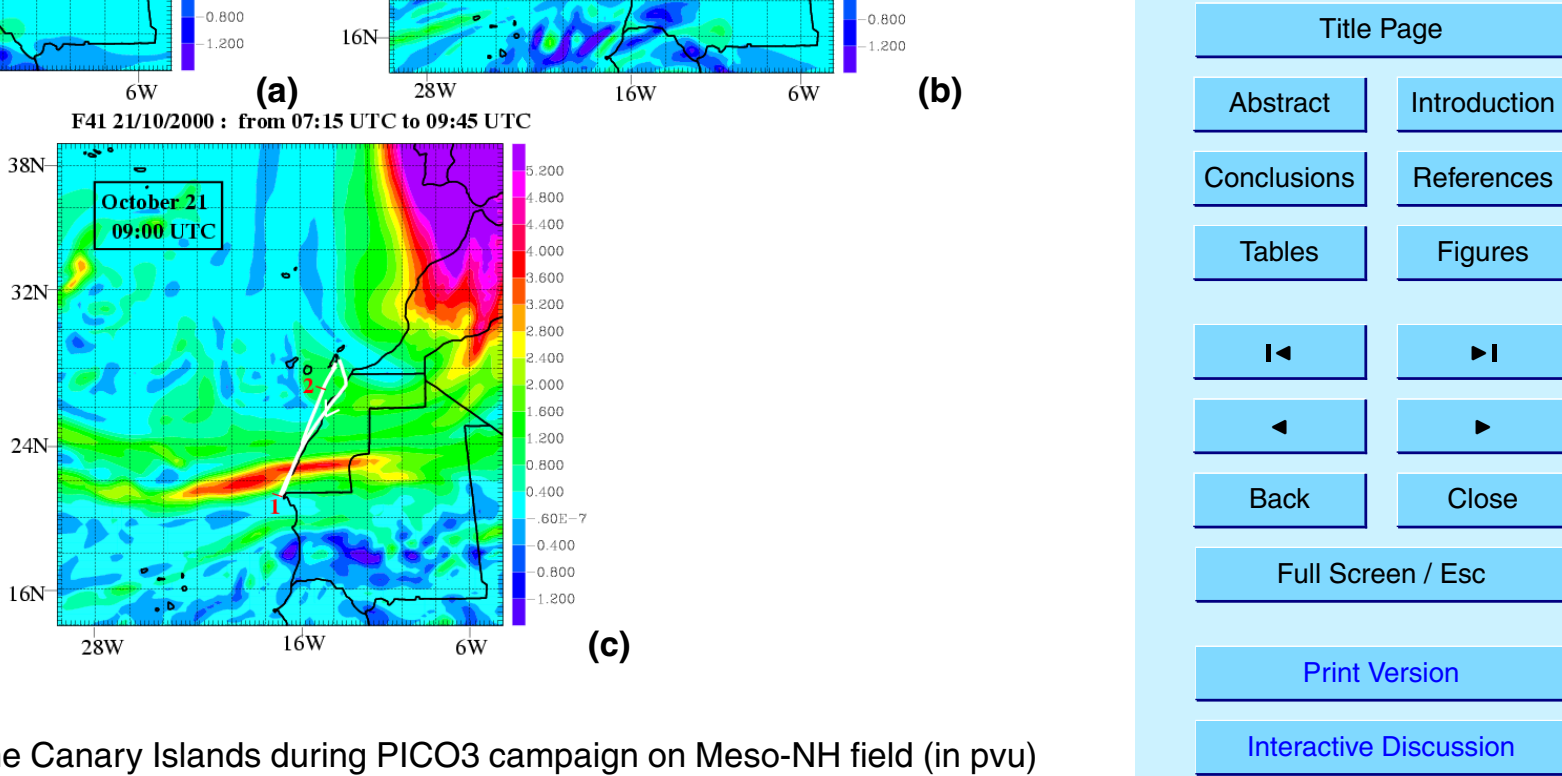

Fig. 2. Flight paths over the Canary Islands during PICO3 campaign on Meso-NH field (in pvu)

Interactive Discussion at $11 \mathrm{~km}$ altitude: (a) Flight 39 over PV field at 15:00 UTC on 20 October. (b) Flight 40 over PV field at 18:00 UTC on 20 October. (c) Flight 41 over PV field at 09:00 UTC on 21 October. The real time occurrence of each flight is reported at the top of each graph. The lines S-N (graph EGU a); T2 (graph b) and marks I, J (graph a); a, b (graph b) and 1, 2 (graph c) will be used in the next sections. 


\section{ACPD}
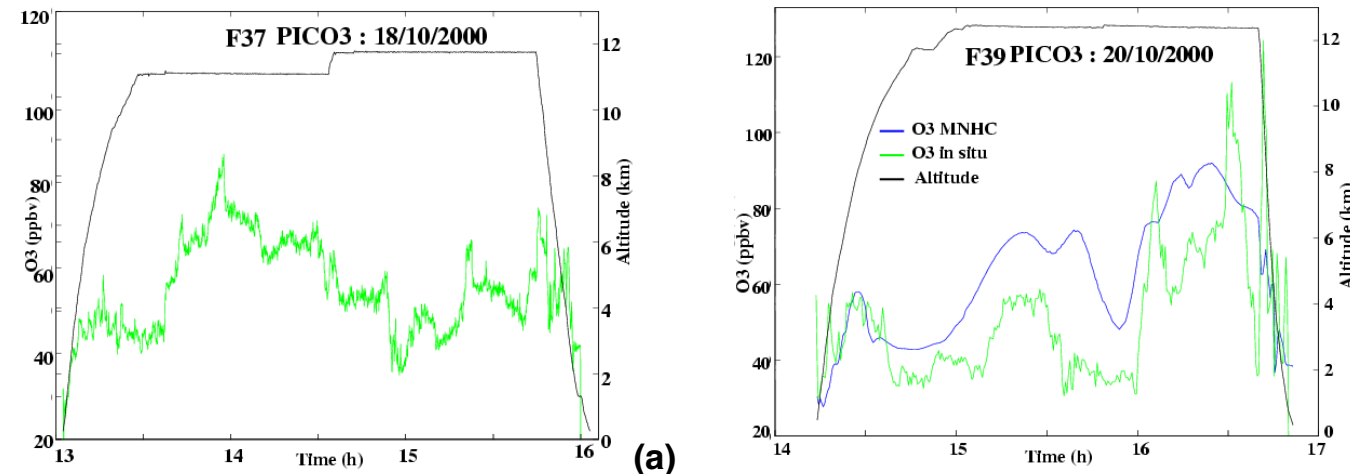

(a)
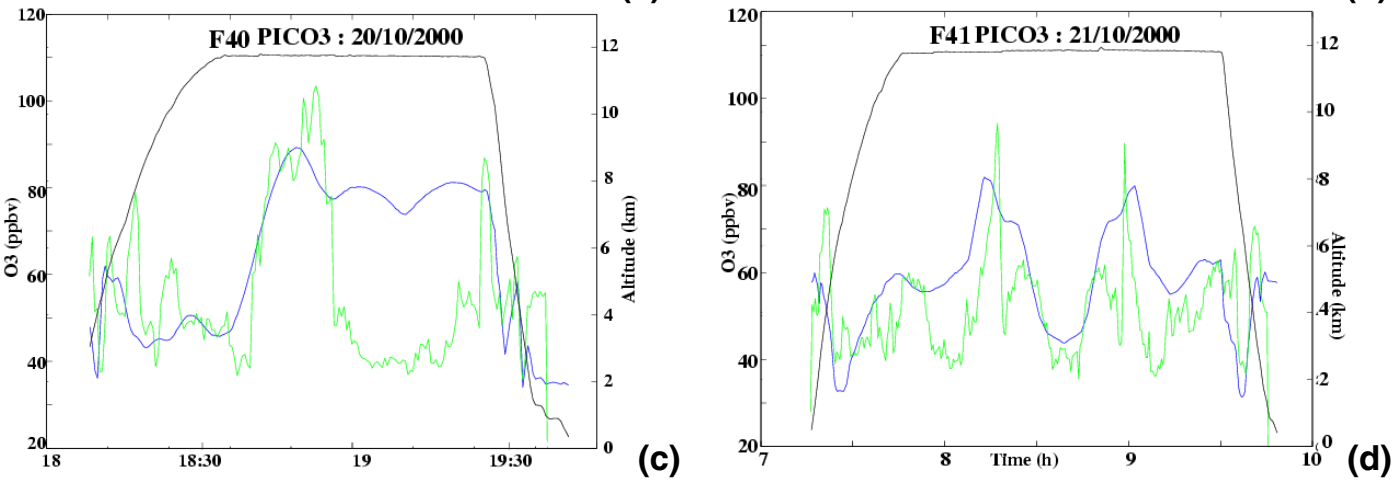

5, 10301-10337, 2005

\section{Stratospheric} intrusions

A. Carré et al.

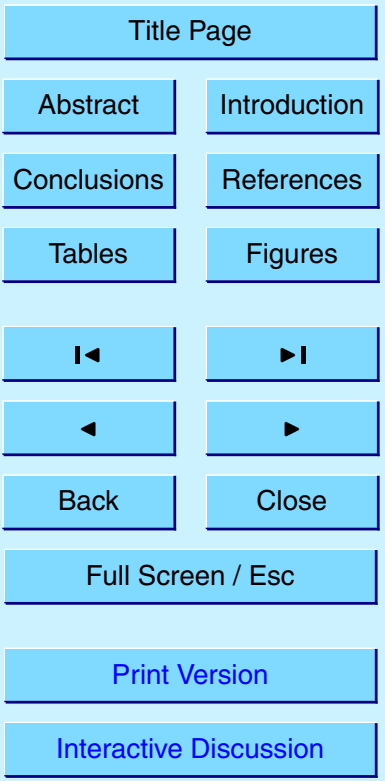

EGU 

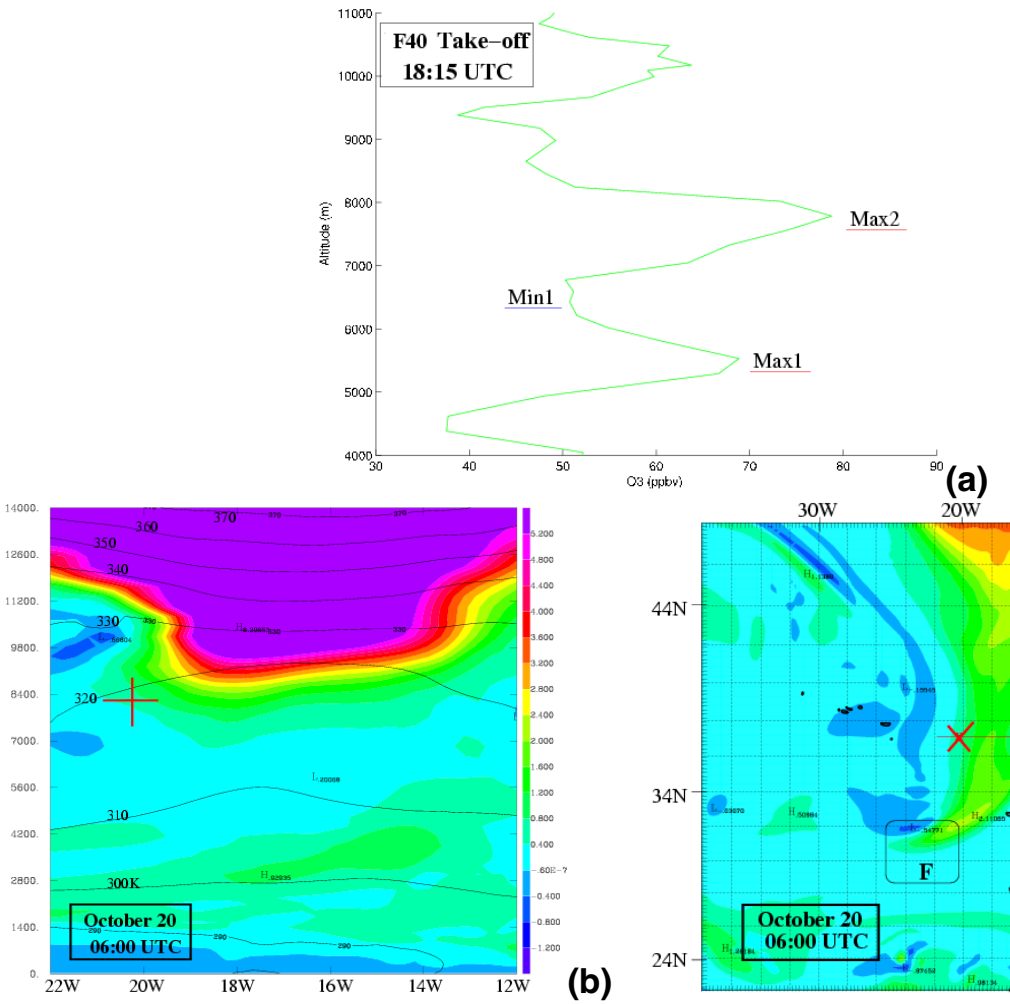

(b)

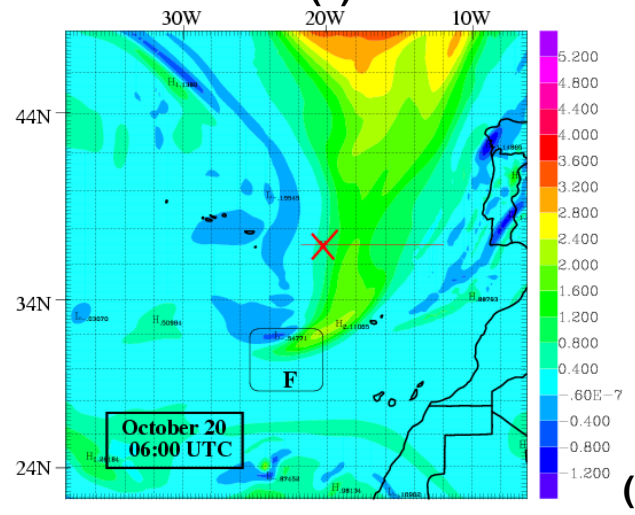

(c)

Fig. 4. (a): Vertical profile of in-situ $\mathrm{O}_{3}$ (ppbv) during the take-off of flight 40, at 18:15 UTC. We investigate strong variations labelled Max1, Max2 (maximum) and Min1 (minimum). (b) and (c): Meso-NH PV (pvu) on 20 October, 06:00 UTC showing the structure of a tropopause fold on a zonal vertical cross-section (in meters) (b) and on a horizontal plane at $8272 \mathrm{~m}$ (c). This is the altitude of the air parcel marked by a red cross situated in the fold at this date. At 18:00 UTC, the red air parcel corresponds to the maximum of $\mathrm{O}_{3}$ labelled Max1. Red line indicates the location of the cross-section. Isolines of potential temperature $(K)$ are plotted on graph (b). Dark box labelled F shows the trough filament discussed in Sect. 2.2.

\section{ACPD}

5, 10301-10337, 2005

\section{Stratospheric intrusions}

A. Carré et al.

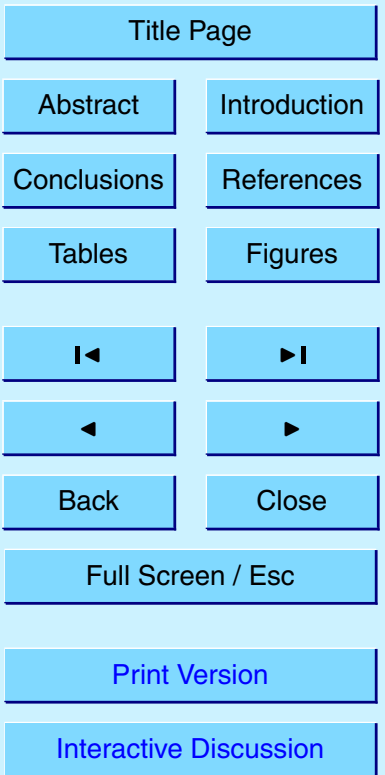

EGU 

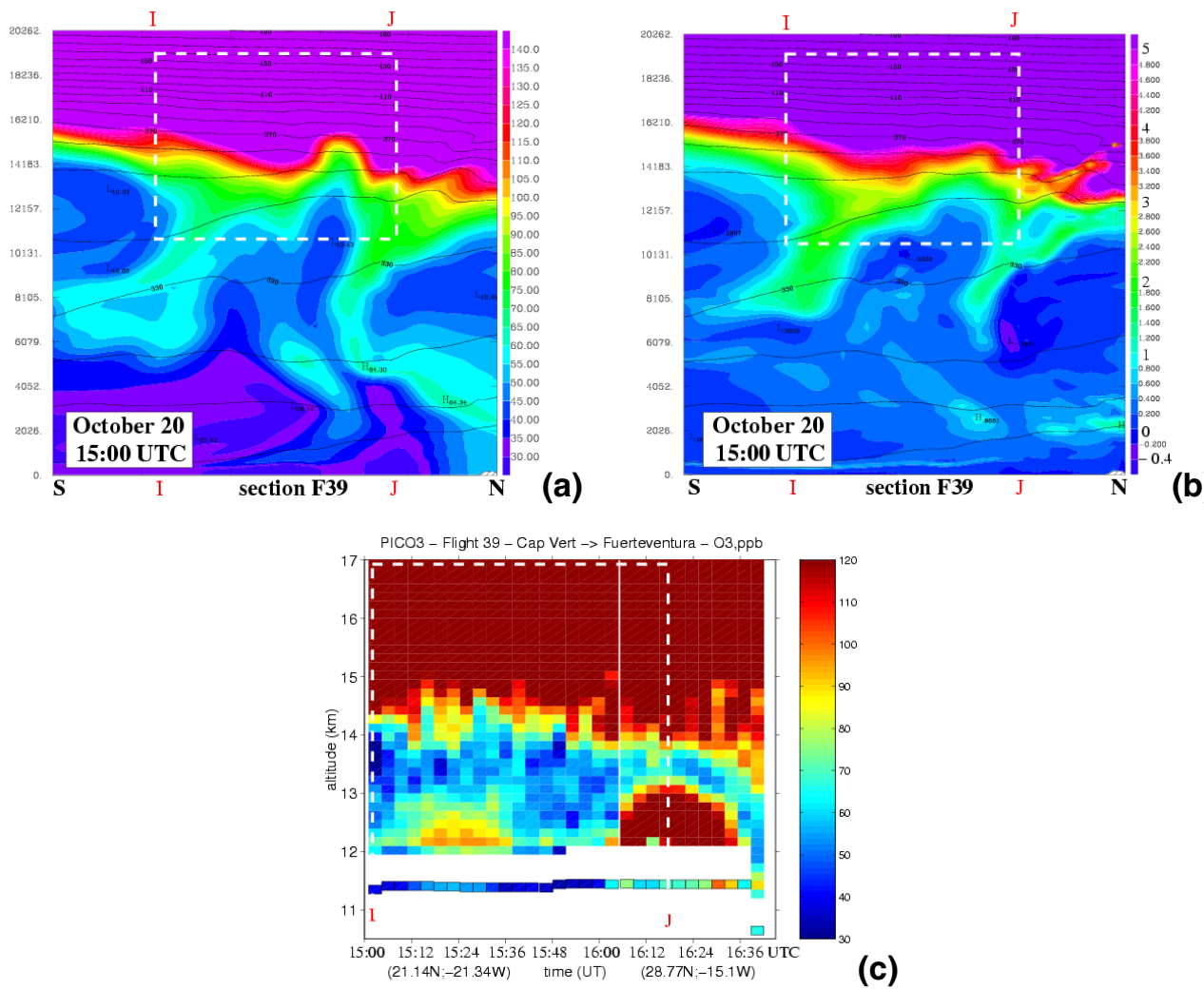

(c)

Fig. 5. (a) and (b): Meso-NH-C vertical cross sections (from South to North) on 20 October, 2000 at 15:00 UTC along the line drawn on Fig. 2a. This section is along the trajectory of flight 39 and includes marks I, J. (a) $\mathrm{O}_{3}$ field (ppbv). (b) PV field (pvu). Altitude is in $\mathrm{m}$. Black lines show isolines of potential temperature (K). (c): Lidar $\mathrm{O}_{3}$ measurement (ppbv) time series during flight 39 between 15:00 UTC and 16:40 UTC. The vertical extension is in $\mathrm{km}$. The dotted colored line indicates the in-situ measurements at the altitude of the aircraft, at the Lidar resolution. The white dashed boxes on the three graphs show the same section of the atmosphere between marks I, J along the flight 39 path.
ACPD

5, 10301-10337, 2005

\section{Stratospheric intrusions}

A. Carré et al.

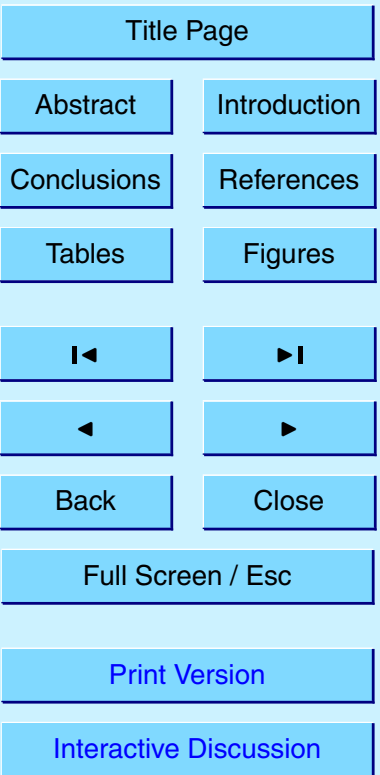

EGU 

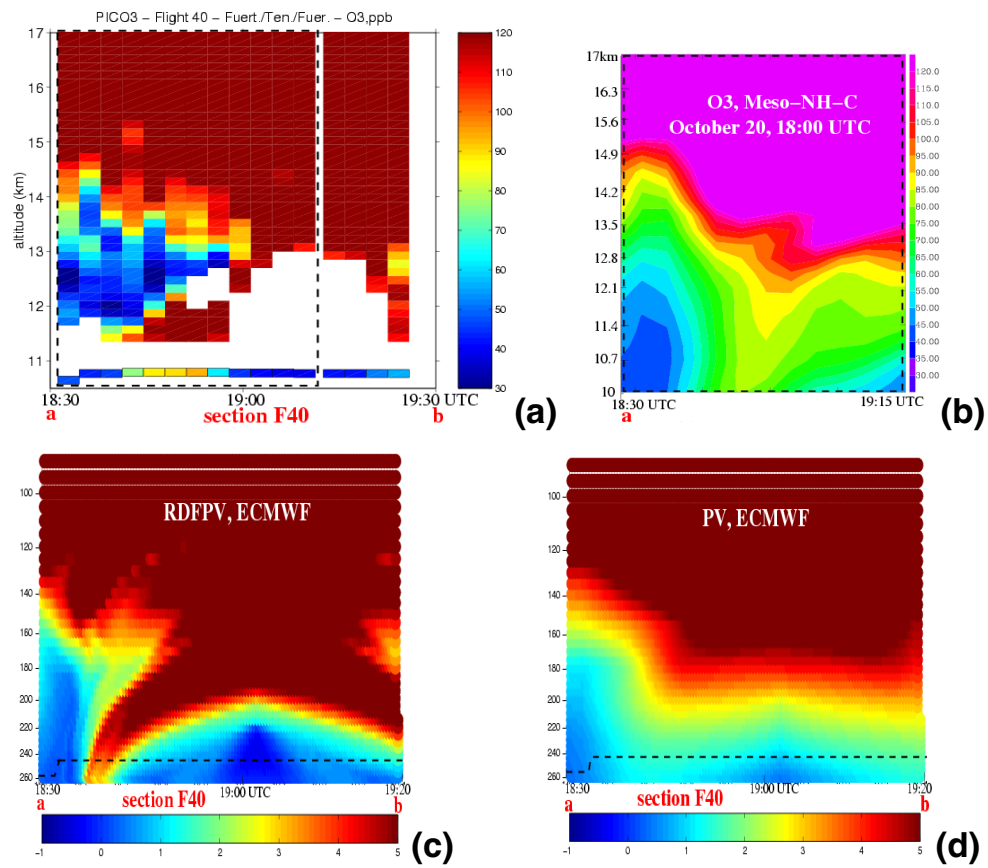

Fig. 6. (a): Lidar $\mathrm{O}_{3}$ measurement (ppbv) time series during flight 40 from 18:30 to 19:20 UTC along path "a-b" (Fig. 2b). The vertical extension is between 11 and $17 \mathrm{~km}$ altitude. The dotted colored line indicates the $\mathrm{O}_{3}$ in-situ measurement at the altitude of the aircraft, at the Lidar resolution. The dotted black box corresponds to the vertical cross-section extension of graph (b). (b): $\mathrm{O}_{3}$ field (ppbv) from Meso-NH-C along a part of flight 40, on the 20 0ctober, 18:00 UTC. Altitude is in $\mathrm{km}$. (c): RDFPV vertical cross-section along the same section of the atmosphere as on graph (a) (flight 40 "a-b"). The vertical extension is in pressure level between 260 and $90 \mathrm{hPa}$, which corresponds to an extension of around $10.5-17 \mathrm{~km}$. Integration time is $24 \mathrm{~h}$, from the ECMWF analysis on 20 October, 18:00 UTC. (d): Corresponding PV from ECMWF analysis on 20 October, 18:00 UTC. Horizontal axis (b, c, d) indicates hours but these times are provided simply for comparison with the time-evolving Lidar measurements. The dashed black line indicates the approximative flight path altitude.

\section{ACPD}

5, 10301-10337, 2005

\section{Stratospheric intrusions}

A. Carré et al.

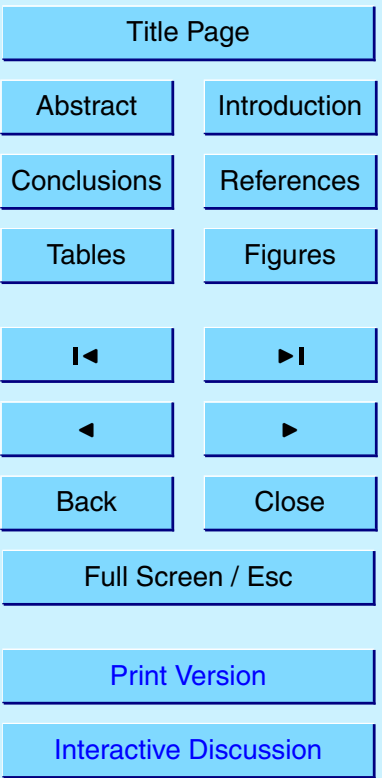

EGU 

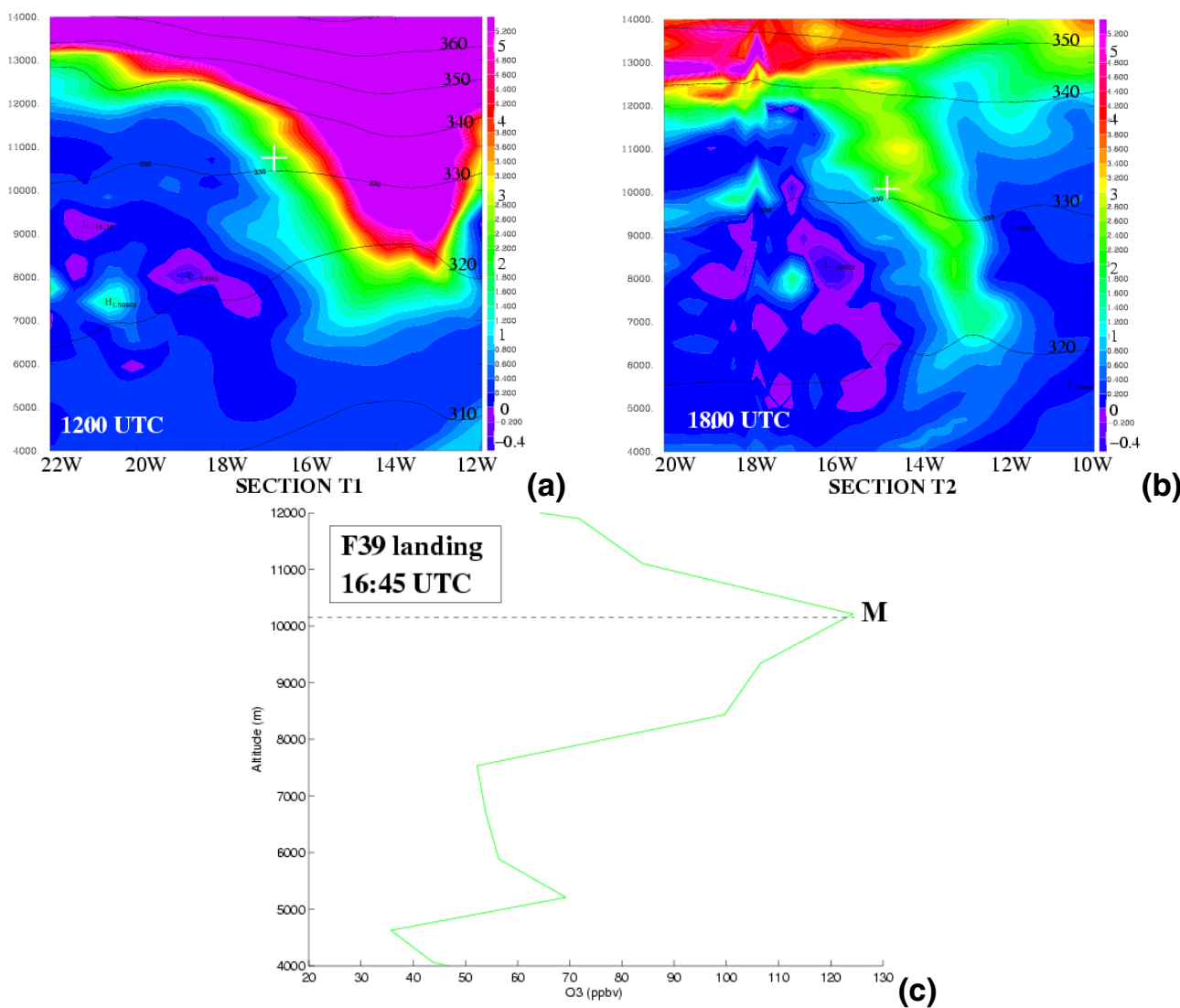

Fig. 7. Zonal vertical cross-sections of PV (pvu) on 20 October 2000, at 12:00 UTC (a) along section "T1" (Fig. 1c) and at 18:00 UTC (b) along section "T2" (Fig. 2b). (c) In-situ sounding of $\mathrm{O}_{3}$ concentration (ppbv) during flight 39 landing. White cross indicates the location into the ULTF of the air parcel corresponding to the maximum M, as seen by Meso-NH backward trajectories.

\section{ACPD}

5, 10301-10337, 2005

Stratospheric intrusions

A. Carré et al.

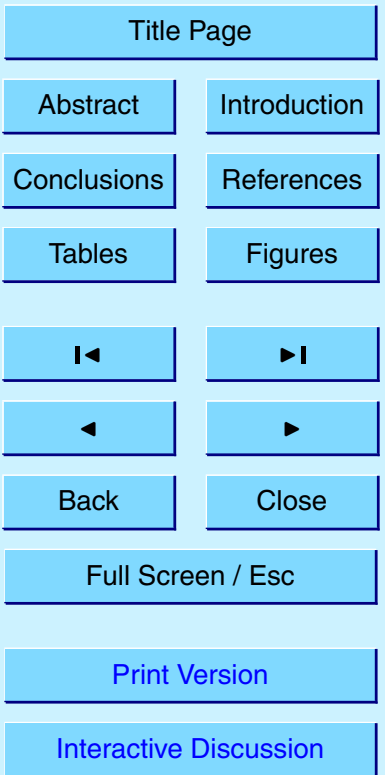

EGU 


\section{ACPD}
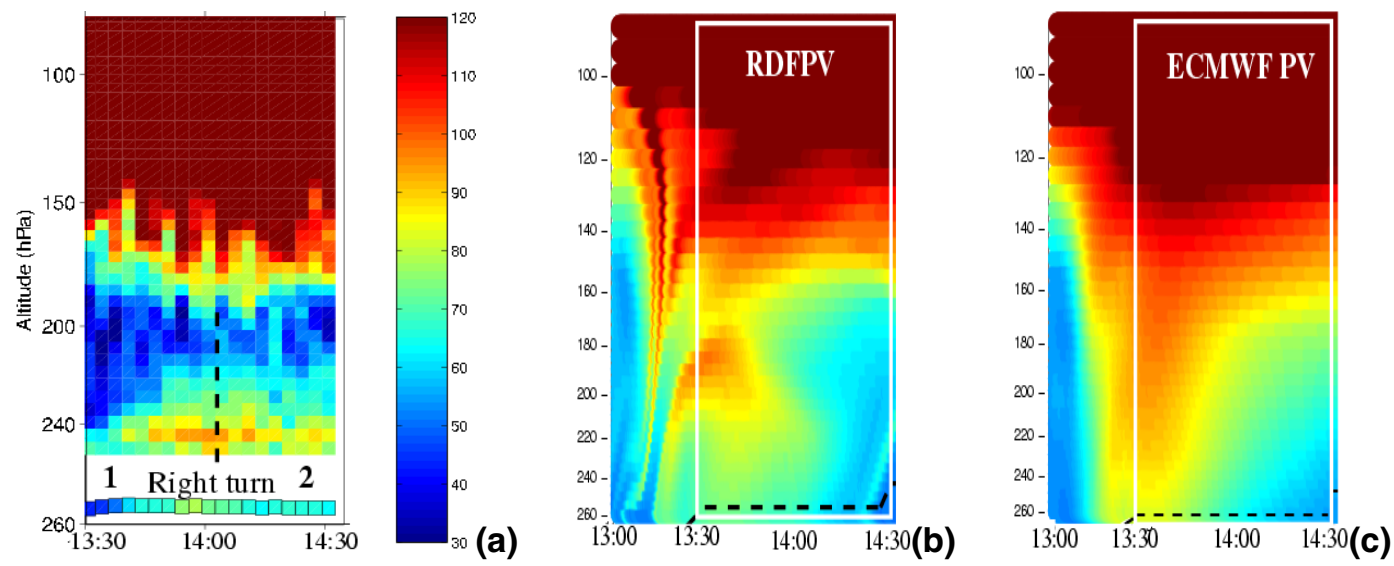

5, 10301-10337, 2005

Stratospheric intrusions

A. Carré et al.
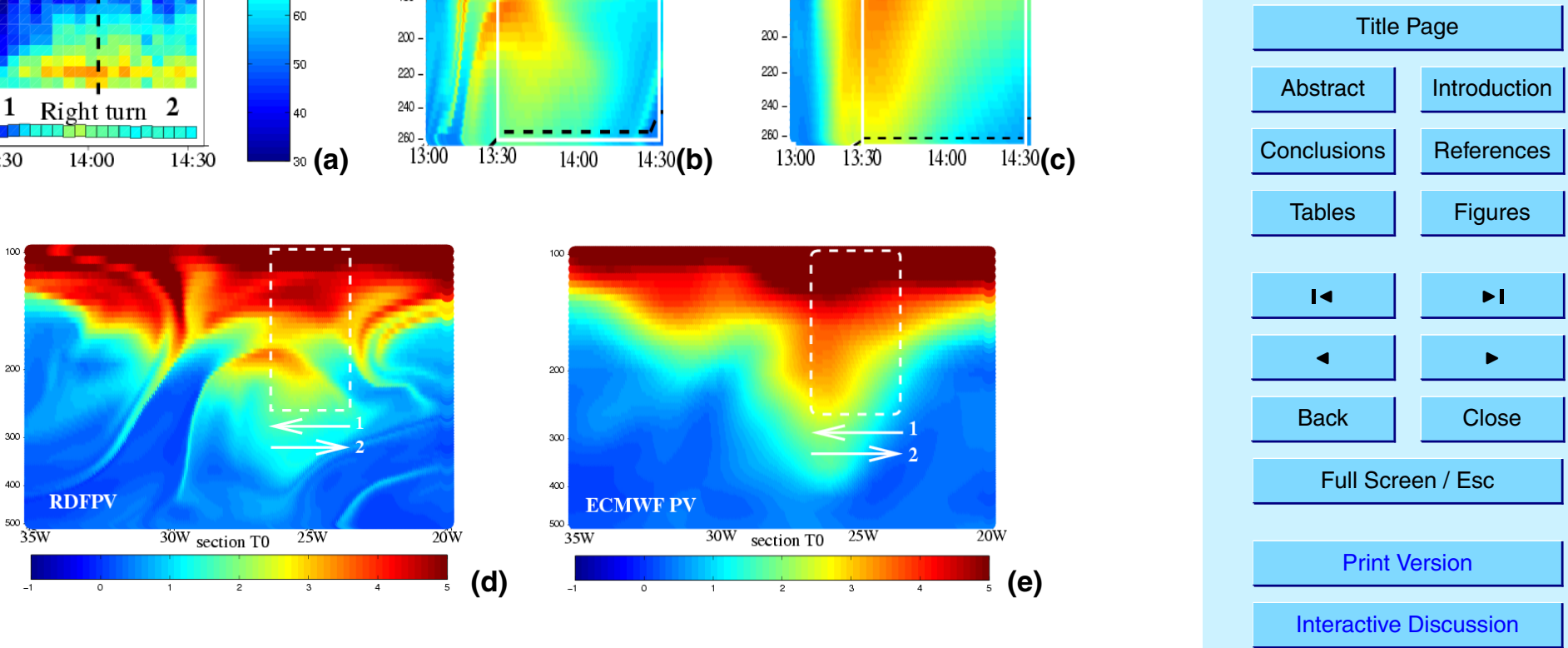

Fig. 8. Caption see next page.

EGU 


\section{ACPD}

$5,10301-10337,2005$

\section{Stratospheric intrusions}

A. Carré et al.

Fig. 8. (a): Lidar $\mathrm{O}_{3}$ measurement (ppbv) time series during the part of flight 37 from 13:30 to 14:30 UTC. The vertical extension is between 260 and $90 \mathrm{hPa}$ on logarithmic scale (it is about from 11 to $17 \mathrm{~km}$ ). The dotted colored line indicates the $\mathrm{O}_{3}$ in-situ measurements at the altitude of the aircraft, at the Lidar resolution. The white box show the section corresponding to the Lidar $\mathrm{O}_{3}$ obersvations. (b): corresponding RDFPV (pvu) vertical cross-section along the flight 37 between 13:00 and 14:30 UTC from the PV of ECMWF analysis on 18 October 2000 at 15:00 UTC (c). The white box corresponds to the Lidar $\mathrm{O}_{3}$ vertical section. Horizontal axis (b, c) indicates hours but these times are provided simply for comparison with the time-evolving Lidar measurements. The dashed black line indicates the approximative flight path altitude. (d): RDFPV along the zonal cross-section T0 plotted on Fig. 1a from the PV of ECMWF analysis on 18 October 2000 at 15:00 UTC (d) plotted along section T0. Dashed white box show the vortex structure sampled during the flight 37 . RDFPV integration time is of $36 \mathrm{~h}(\mathrm{~b}, \mathrm{~d})$.

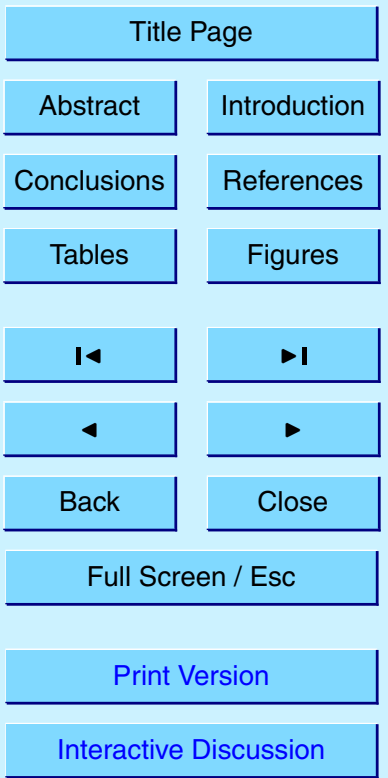

EGU 


\section{ACPD}

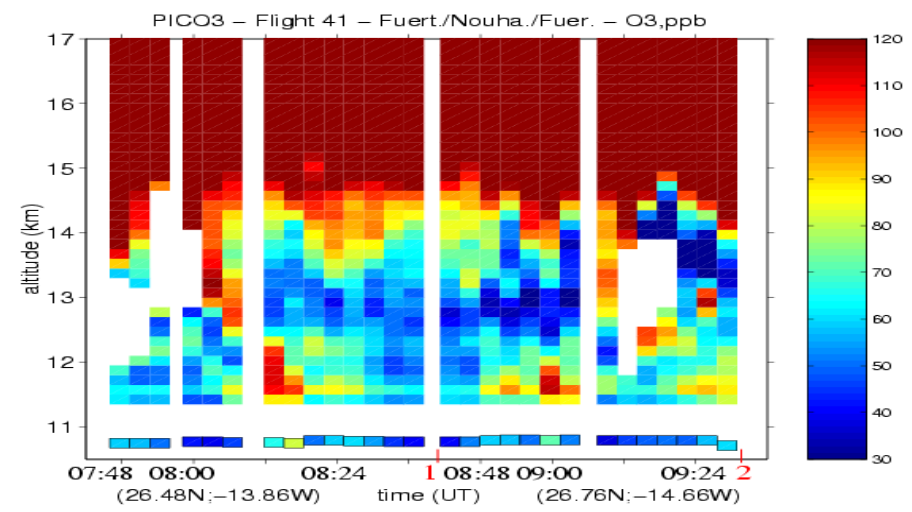

(a)

5, 10301-10337, 2005

Stratospheric intrusions

A. Carré et al.
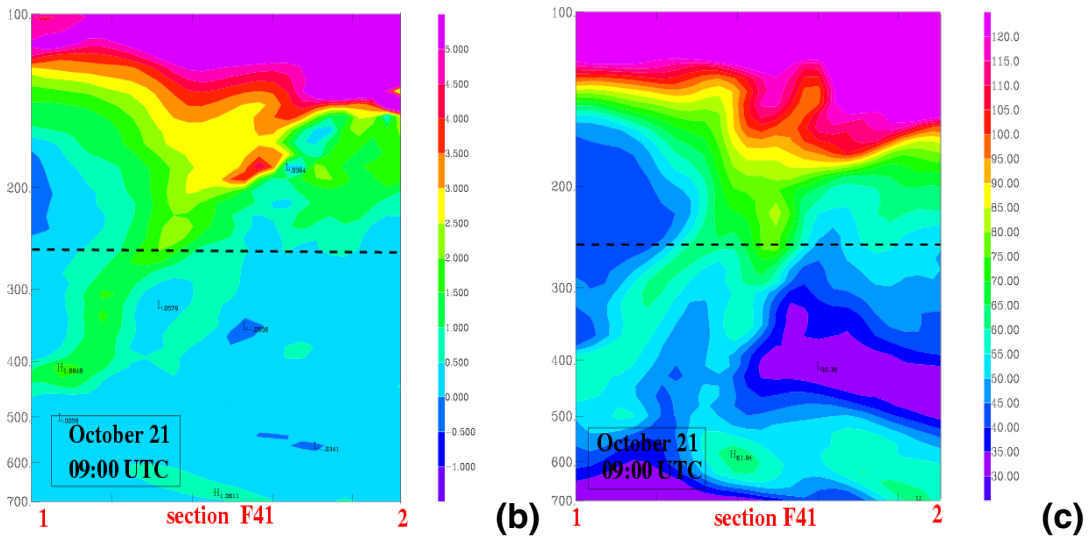

Title Page

\begin{tabular}{|c|c|}
\hline Abstract & Introduction \\
\hline Conclusions & References \\
\hline Tables & Figures \\
\hline
\end{tabular}

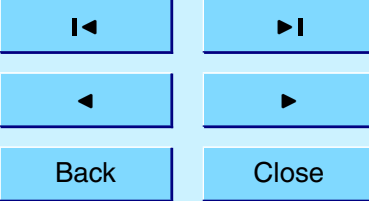

Full Screen / Esc

Print Version

Interactive Discussion

Fig. 9. Caption see next page. 


\section{ACPD}

5, 10301-10337, 2005
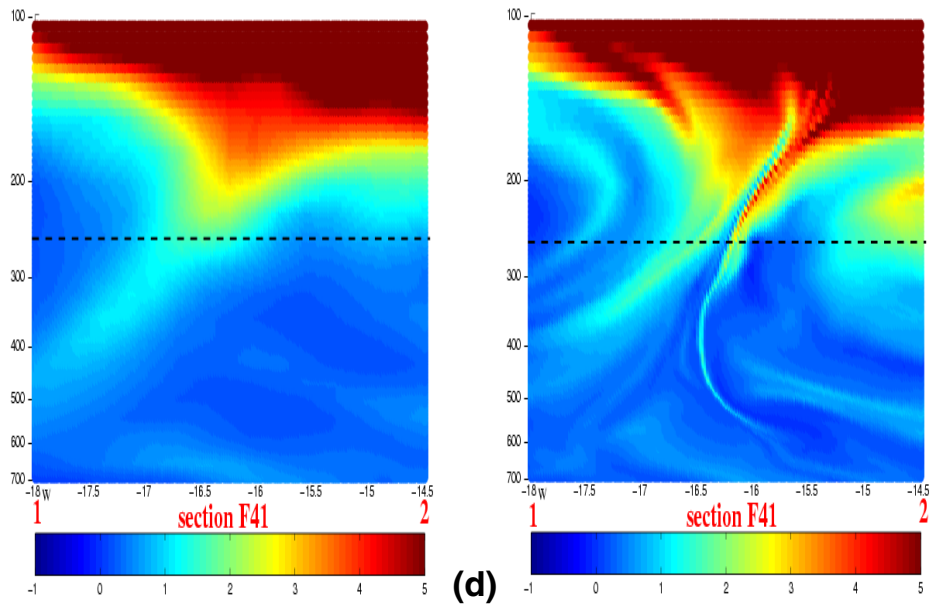

(e)

\section{Stratospheric intrusions}

A. Carré et al.

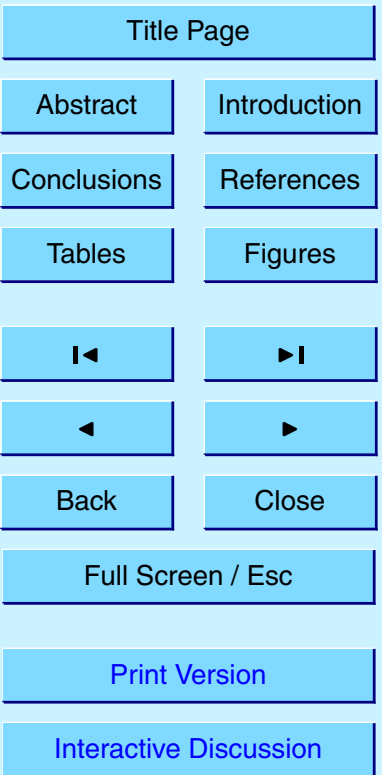

EGU 


\section{ACPD}

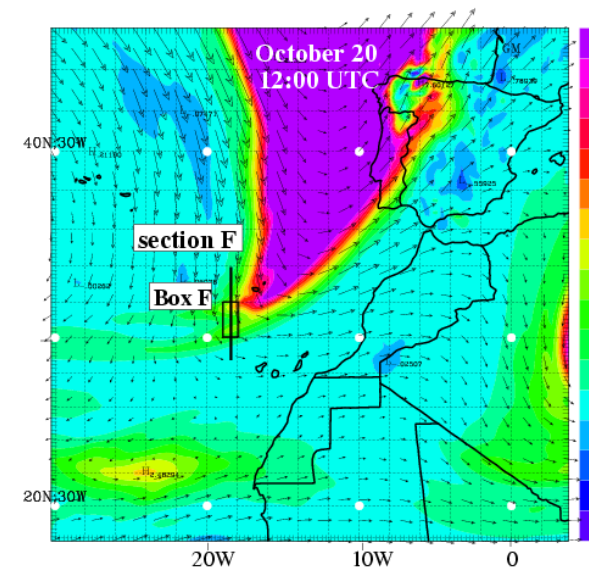

(a)

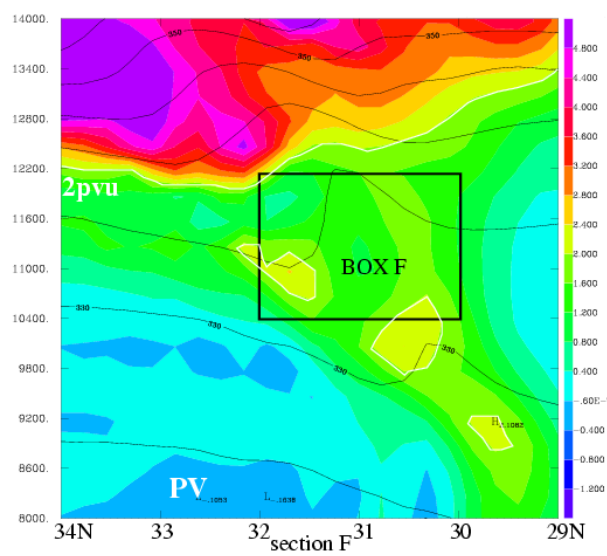

(b)
$5,10301-10337,2005$

\section{Stratospheric} intrusions

A. Carré et al.

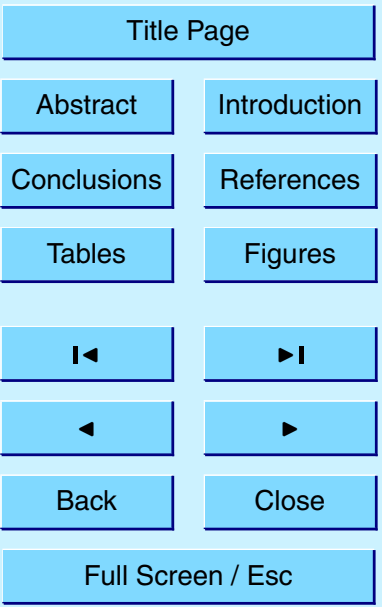

Print Version

Interactive Discussion
Fig. 10. Location of the initial 3-D box $F$ taken in the ULTF on 20 October, 12:00 UTC for computation of a Meso-NH forward plume. (a): Meso-NH PV field (pvu) at $11 \mathrm{~km}$. Horizontal wind is superimposed and plotted as vectors (the largest represent a wind of about $70 \mathrm{~m} / \mathrm{s}$ ). (b): vertical cross-section of PV at $18.5^{\circ} \mathrm{W}$ from $34^{\circ} \mathrm{N}$ to $29^{\circ} \mathrm{N}$. 


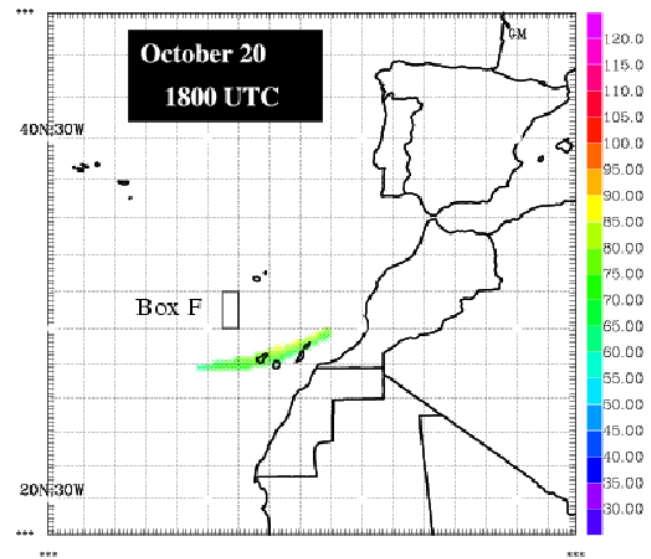

(a)

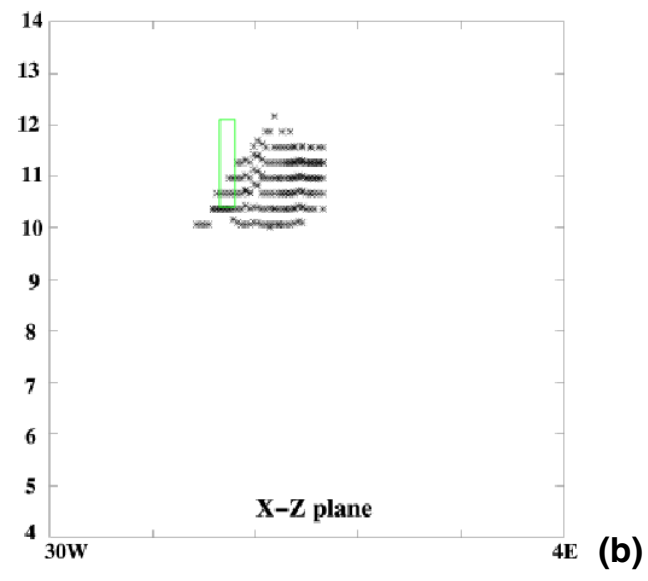

\section{ACPD}

5, 10301-10337, 2005

Stratospheric intrusions

A. Carré et al.
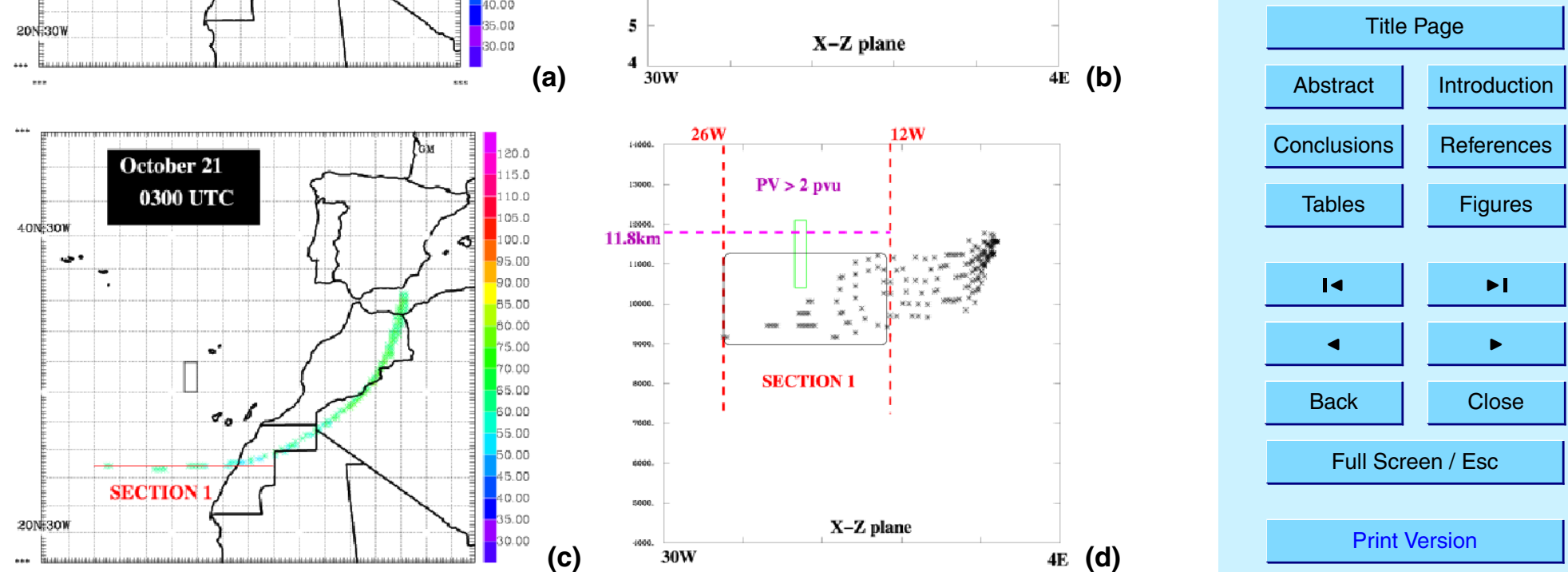

Interactive Discussion

Fig. 11. Caption see next page.

EGU 


\section{ACPD}

5, 10301-10337, 2005

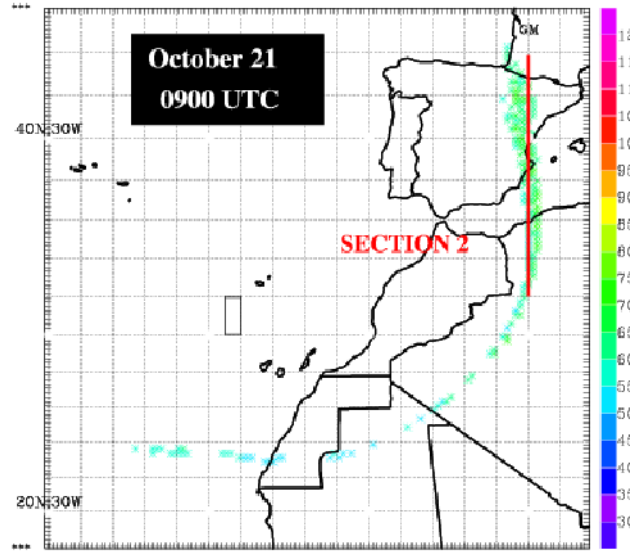

(e)

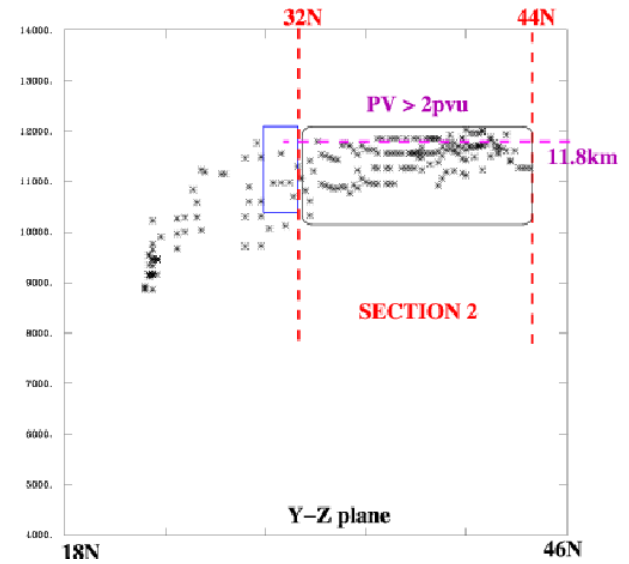

(f)

\section{Stratospheric intrusions}

A. Carré et al.

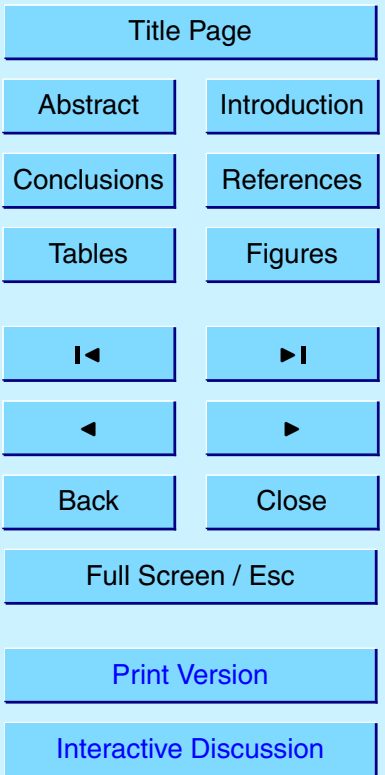

EGU 